\title{
Análise de possíveis determinantes da penetração do serviço de acesso à internet em Banda Larga nos municípios brasileiros *
}

\author{
Hildebrando Rodrigues Macedo \\ Alexandre Xavier Ywata de Carvalho ${ }^{* * *}$
}

\begin{abstract}
Resumo
Analisou-se o panorama geral da penetração do serviço de acesso à internet em Banda Larga nos municípios brasileiros, bem como utilizou-se análise de regressão de dados em cross-section, para se avaliar como alguns fatores referentes ao desenvolvimento econômico e humano relacionam-se com a penetração do serviço. Utilizaram-se indicadores econômicos (como PIB per capta, PIB e sua distribuição entre os setores Agropecuário, Industrial e de Serviços de 2007) e o Índice Firjan de Desenvolvimento Humano de 2005 (para Educação, Emprego \& Renda e Saúde). Os dados dos acessos de Banda Larga de 2007 procedem da Anatel. As conclusões mostram grande concentração no mercado de Banda Larga nos municípios, bem como apontam aqueles onde predominam o PIB oriundo de atividades industrial e de serviços, em detrimento à agricultura como mais favoráveis a maiores penetrações de Banda Larga. O estudo permite subsidiar propostas de políticas públicas de inclusão digital.
\end{abstract}

Palavras-chave: Banda larga; Impacto econômico; Telecomunicações; Difusão de tecnologia.

\section{Abstract \\ An analysis of the possible determinants of Broadband internet access penetration in Brazilian municipalities}

A general overview of broadband internet access across Brazilian municipalities was made; and by using cross-section regression analysis, the economic and human development factors affecting the diffusion of this service were studied. Economic development indicators including GDP per capita and GDP and how it is distributed among the Agricultural, Industrial and Services sectors for the year 2007, were used. Regarding human development indicators, the Firjan Human Development Index for the year 2005 was utilized. Broadband accesses data from 2007 came from Anatel. The conclusions show a high concentration of broadband access at the municipality level, as well as indicating that localities where GDP comes predominantly from industrial and services sectors, when compared to agricultural activities, tend to have a higher broadband penetration. This study highlights information that could be used to implement public policies aiming to increase the digital inclusion.

Keywords: Broadband; Economic impact; Telecommunications; Technology diffusion. JEL C21, O33.

\footnotetext{
* Trabalho recebido em 7 de março de 2010 e aprovado em 29 de março de 2012

** Especialista em Regulação de Serviços de Telecomunicações, Agência Nacional de Telecomunicações, Anatel, Brasília, DF, Brasil. E-mail: hrmacedo@gmail.com.

*** Técnico de Planejamento e Pesquisa da Diretoria de Estudos e Políticas Regionais, Urbanas e Ambientais (Dirur) do Instituto de Pesquisa Econômica Aplicada (Ipea), Brasília, DF. E-mail: alexandre.ywata@ipea.gov.br.
} 


\section{Introdução}

Os investimentos na ampliação das redes de telecomunicações levam ao crescimento econômico dos países, conforme demonstrado em diversos estudos. Devido ao impacto econômico positivo da ampliação das redes de acesso à internet em Banda Larga, o Poder Público em diversos países tem tomado ações para tentar tornar o acesso a este serviço mais difundido entre a população. Em parte, tais iniciativas buscam como legitimidade a identificação dos efeitos de rede e externalidades positivas geradas pela ampliação das redes de Banda Larga, como mencionam Mayo e Wallsten (2011, p. 175).

Um exemplo desta externalidade positiva, também mencionado por Mayo e Wallsten (2011, p. 180), é o impacto da Banda Larga sobre a criação de empregos, conforme o estudo de Crandall, Lehr e Litan (2007, p. 2), cujos resultados indicaram que a cada 1 ponto percentual de aumento na penetração de Banda Larga, haveria um aumento de 0,2 a 0,3 ponto percentual na taxa de crescimento do nível de emprego.

Diversos estudos quantificaram o impacto econômico do aumento da penetração de Banda Larga, como por exemplo, o do Banco Mundial, de Qiang, Rossoto e Kimura (2009) que analisou dados de cerca de 120 países referentes à penetração dos serviços de telecomunicações e de desenvolvimento econômico. Suas conclusões indicam que, para países em desenvolvimento, a cada ponto percentual de aumento da penetração do serviço de Banda Larga, haveria aumento de 0,138 ponto percentual na taxa de crescimento do PIB per capita.

Outro exemplo é o estudo de Koutroumpis (2009, p. 478), utilizando sistema de equações simultâneas de oferta e demanda com variáveis endógenas, analisando dados de 22 países da OECD entre 2002 e 2007, cujos resultados indicam que cada 1 p.p. (ponto percentual) de aumento da penetração de Banda Larga estaria relacionado com o crescimento do PIB entre 0,012 e 0,204 p.p.

Aplicando a metodologia de Koutroumpis (2009) para o Brasil, em Macedo e Carvalho (2010 e 2011), os resultados encontrados indicam que a cada 1p.p. de aumento da penetração de Banda Larga estaria relacionado com crescimento do PIB entre 0,038 e 0,18 p.p. e crescimento do PIB per capita entre 0,196 e 0,362 p.p.

Estes estudos destacam a importância das redes de telecomunicações de Banda Larga como fator aceleração do desenvolvimento econômico. Ou seja, enfatizam seu papel transformador das atividades econômicas, de importância similar aos benefícios trazidos por outras redes de infra-estrutura como as de ferrovias, energia elétrica, rodovias e outras. 
Nos Estados Unidos, o governo lançou, em 2009, um plano para tornar este serviço acessível de forma mais ampla, em particular para as áreas rurais, como anunciado pelo FCC (2009).

$\mathrm{Na}$ Espanha, o governo pretende ampliar o acesso em Banda Larga, estabelecendo que o acesso com velocidade mínima de $1 \mathrm{Mbps}$ seja universal, como definido em uma lei de 2011. (Espanha, 2011, art. 52, p. 25035).

No Brasil, o Governo Federal tomou uma iniciativa similar, lançando seu Plano Nacional de Banda Larga - PNBL, como divulgada pelo Ministério das Comunicações, (Brasil, 2009). Seu objetivo é ampliar a rede de infra-estrutura de telecomunicações que dá suporte à prestação do serviço de acesso à internet em Banda Larga, tendo como foco principal os municípios menores, onde a disponibilidade do serviço é deficiente.

Esta infra-estrutura consiste de uma rede de fibras ópticas, chamada de backhaul, que permite maiores capacidades de transmissão de dados, utilizando as redes existentes de empresas estatais como Eletrobrás e Petrobrás, além de outros entes públicos, a ser administrada pela Telebrás reativada com o aporte de recursos públicos.

Fazendo uma analogia com as rodovias, o backhaul é como se fosse uma rede de estradas vicinais, levando o tráfego de dados do município ao backbone, uma rede de dados em alta velocidade que interliga o país inteiro, representando o papel da rede de rodovias principais.

A intenção é a de que a Telebrás atue majoritariamente no mercado de atacado, ofertando enlaces dedicados de transmissão de dados em altas velocidades, os chamados links (ou linhas) dedicados. Isto porque este mercado é dominado pelas concessionárias que prestam o serviço de telefonia fixa, cobrando valores elevados pelo serviço. Isto dificulta a entrada de novos provedores de Banda Larga nos municípios, frequentemente pequenas empresas, uma vez que estes necessitam contratar estas linhas dedicadas para poder ofertar o acesso ao usuário final. Os preços elevados das linhas dedicadas drenam recursos destes pequenos provedores dificultando sua viabilidade econômica.

O entendimento, segundo o PNBL, é o de que atuando no mercado de atacado, ofertando linhas dedicadas a preços mais acessíveis e competindo com as grandes empresas de telecomunicações, a Telebrás facilitaria a entrada de novos competidores no mercado de varejo de Banda Larga que atende ao usuário final.

Também no Brasil foram feitos estudos relacionando investimento em infra-estrutura de telecomunicações e desenvolvimento econômico. Em Gomes (2002), foi feita uma análise de causalidade, com o teste de Granger, identificando relacionamento positivo entre aumento do número de telefones fixos e evolução do PIB, entre 1973 e 2000. 
Em Moraes (2008, p. 52, 62), com análise de dados em painel estudando a relação entre aumento do número de telefones móveis celulares com o aumento do PIB per capita, encontrou-se resultados que indicam que a cada ponto percentual de aumento da densidade de telefones móveis celulares no Brasil, o PIB per capita aumentaria cerca de 0,07 p.p.

No estudo Ipea (2010), é feita uma radiografia do setor de Banda Larga no Brasil, propondo ações para a ampliação do acesso de Banda Larga para a população.

Além do impacto econômico, a maior disponibilização do acesso em Banda Larga para a população em geral traz outros benefícios, auxiliando nas políticas de inclusão social. Isto, pois o acesso à internet permite: o alcance de um universo de informações e recursos (como ensino à distância), a busca de oportunidades de trabalho, além de ter um papel no fortalecimento da democracia no país, por ampliar a diversidade de fontes de informação, diminuindo a influência dos grandes meios de comunicação de massa como Rádio e TV.

Para o planejamento de políticas públicas voltadas para o setor, é relevante se estudar quais fatores estão relacionados com o aumento da difusão do acesso à internet em Banda Larga ao nível dos municípios. Os dois principais objetivos deste trabalho são:

1) Apresentar um panorama geral da penetração do serviço de acesso à internet em Banda Larga no país, mostrando a desigualdade existente na oferta do serviço que se concentra excessivamente nas grandes cidades, deixando à margem os pequenos municípios, onde o mercado de Banda Larga é muito concentrado, sendo praticamente dominado pelas operadoras de telefonia fixa. Assim, este diagnóstico pretende fornecer alguns subsídios para a elaboração de políticas públicas visando aumentar a disponibilidade do serviço de Banda Larga aos cidadãos.

2) Relacionar a penetração do serviço de acesso à internet em Banda Larga nos municípios brasileiros com alguns indicadores de desenvolvimento econômico e humano como: a) PIB per capita do município, b) tamanho da população, c) distribuição do PIB municipal entre as áreas de agricultura, indústria e de serviços, d) número de prestadoras do serviço de acesso à internet em Banda Larga presentes no município, bem como o grau de competição entre estas, e) indicadores sociais do nível de desenvolvimento do município, referentes a saúde, educação e emprego e renda. Vale lembrar que a análise foi feita empregando regressão de dados em cross-section.

A hipótese inicial foi a de que em municípios com melhores indicadores de desenvolvimento econômico e humano, a penetração do serviço seria maior. E também, a de que municípios com maior parte de seu PIB sendo proveniente do setor de serviços teriam maior propensão à penetração da Internet em Banda Larga. 
Os dados do número de acessos de Banda Larga por município são provenientes da Anatel - Agência Nacional de Telecomunicações e do PIB municipal do IBGE, ambos de 2007. Os indicadores de desenvolvimento humano são referentes a 2005, obtidos de um estudo da Firjan - Federação das Indústrias do Estado do Rio de Janeiro, que desenvolveu indicadores de desenvolvimento, em nível de município, relativos à renda, saúde e educação.

Para avaliar como o grau de competição na prestação do serviço de Banda Larga nos municípios afeta a penetração deste, foram calculados para os municípios analisados, o Índice Herfindahl-Hirschman (HHI), Hirschman (1964), relativo à competição entre empresas e entre tecnologias usadas na prestação do serviço, com dados da Anatel de 2007.

\section{Referências}

Estudos anteriores analisaram determinantes da penetração de Banda Larga. De maneira geral, suas as conclusões destacam, por um lado, o preço como afetando negativamente a penetração do serviço e, por outro, a competição entre tecnologias, bem como a possibilidade de compartilhamento de infra-estrutura entre operadoras, como aceleradores da difusão do serviço.

O compartilhamento da infra-estrutura de redes usadas na prestação de Banda Larga é chamado de unbundling, ou desagregação de redes, onde uma prestadora de serviços de telecomunicações utiliza a infra-estrutura de outra, mediante o pagamento pelo seu uso. Outros fatores afetam, em menor grau, positivamente a penetração como: a maior renda, a escolaridade, a concentração demográfica, entre outros.

Benkler (2009, p. 69) fez uma regressão de dados em cross-section, replicando um estudo anterior de Turner (2006) para identificar os fatores que influenciam a penetração de Banda Larga em 30 países da OECD, utilizando dados de outubro a dezembro de 2008. O fator de maior impacto foi a renda. Este autor também fez uma revisão das políticas públicas de diversos países para o setor (p. 75), destacando o grande benefício trazido pelas políticas de unbundling para o aumento da penetração da Banda Larga.

Lee e Brown (2008) também utilizaram análise de dados em crosssection com amostras de 110 países. Utilizaram dados referentes a características como renda, escolaridade, densidade demográfica, preço do serviço, velocidade de conexão e competição entre diversas tecnologias de prestação do serviço de Banda Larga bem como a existência de políticas que favoreçam o compartilhamento de redes. Os autores destacam o compartilhamento de redes (unbundling) e a competição entre tecnologias como os principais fatores que influenciam o aumento da penetração de Banda Larga. 
Já a conclusão de Garcia-Murillo (2005) é a de que a adoção de políticas de unbundling favorece a penetração de Banda Larga em países de menor renda, tendo pouco efeito em países mais ricos.

Dada a dificuldade de se encontrar indicadores recentes e confiáveis do nível de desenvolvimento humano, desagregados por municípios, foi utilizado como aproximação o indicador definido pela Firjan (2005) para avaliar como as diferenças do nível de desenvolvimento entre municípios relacionam-se com a penetração de Banda Larga.

\section{Visão geral da distribuição dos acessos de banda Larga no Brasil}

Antes de entrar na análise econométrica, é apresentada uma visão geral de como os acessos de Banda Larga são mais concentrados nos grandes centros urbanos, enquanto que, nas pequenas cidades, a penetração é bastante baixa, como mostra a Figura 1. Os dados do estudo indicam que, em 2007, cerca de $8 \%$ dos municípios não contavam com qualquer acesso de Banda Larga no país.

Estas informações, juntamente com os resultados das análises dos modelos econométricos, permitem ter uma visão mais completa do setor e fornecem subsídios para a ação de políticas públicas visando o aumento da penetração de Banda Larga no país.

Visualmente comparando-se as Figuras 1 e 2 percebe-se uma maior penetração do serviço nas localidades com disponibilidade de infra-estrutura de Banda Larga.

\section{Figura 1}

Cartograma mostrando a densidade de acessos de Banda Larga a cada mil habitantes, por município.

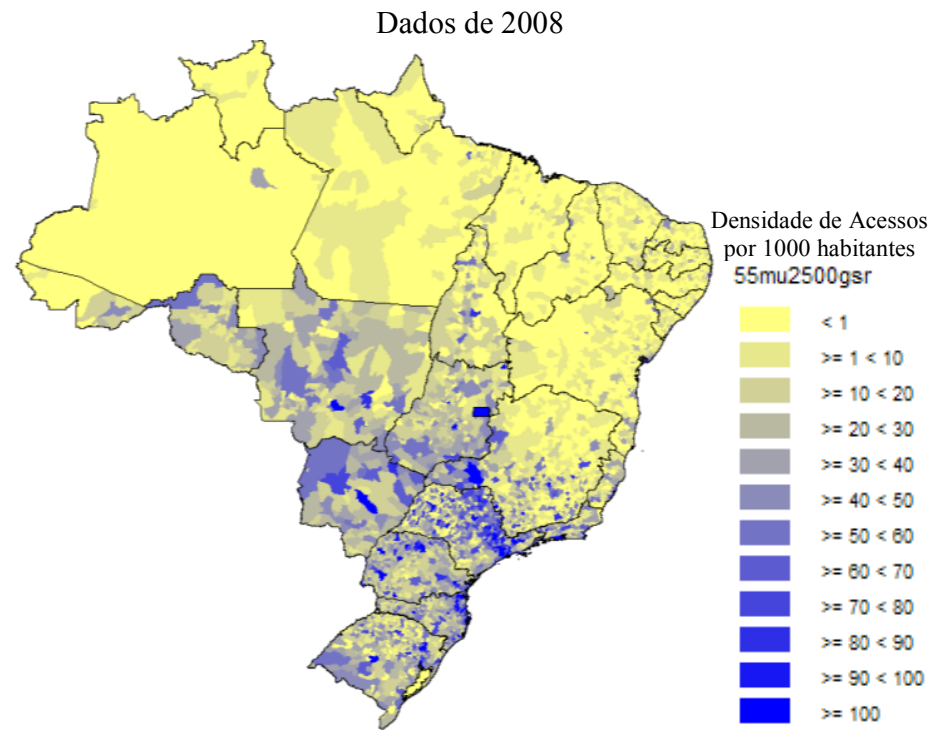

Fonte: Elaborado pelos autores a partir de dados de Anatel-SICI. 
Figura 2

Municípios que possuem infra-estrutura de backhaul

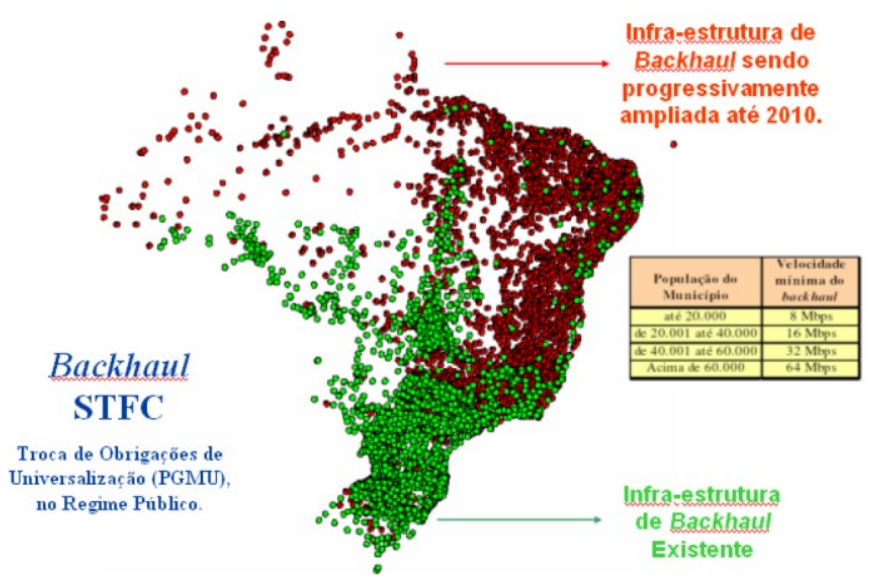

Fonte: extraído do Plano Nacional de Banda Larga - PNBL. (Brasil, 2009, p.40).

Nos Gráficos 1, 2 e 3 são apresentadas informações sobre a evolução do número de prestadoras e de acessos de Banda Larga no país, bem como estes acessos estão distribuídos por velocidade e tecnologia.

No Gráfico 1 vê-se a existência de mais de 2.300 provedores de Banda Larga no país. São empresas autorizadas a prestar o Serviço de Comunicação Multimídia, segundo a regulamentação da Anatel, que exige uma autorização para prestar o serviço. Na grande maioria são pequenos provedores atuando em cidades pequenas, com menos de 50.000 habitantes prestando o serviço por meio de tecnologias de acesso sem fio. Apesar do grande número, correspondem a uma pequena parcela do total de acessos de Banda Larga, tendo aproximadamente 5\% dos acessos, segundo os dados de Anatel-SICI e que aparecem no Gráfico 3 como acessos com a tecnologia sem fio.

Dados da Anatel indicam crescimento acima de $30 \%$ ao ano no número de acessos de Banda Larga, apesar dos elevados preços cobrados pelo serviço. Isto talvez se explique pela percepção de que, se não tiver acesso a este serviço, o cidadão comum será um excluído digital, não tendo acesso a diversas oportunidades de desenvolvimento individual proporcionados pela ampla quantidade e diversidade de informações disponibilizadas na internet. 


\section{Gráfico 1}

Evolução do número de acessos de Banda Larga e do número de prestadoras de Banda Larga

(Serviço de Comunicação Multimídia, conforme definição da Anatel).

Dados até o final do $3^{\circ}$ trimestre de 2010

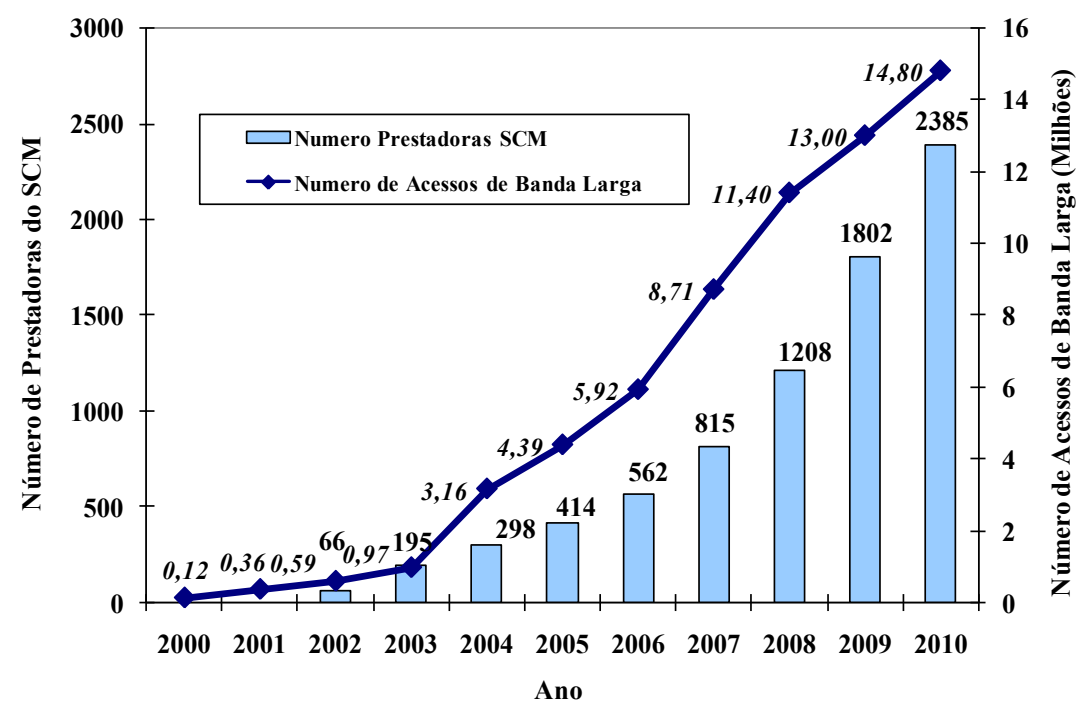

Fonte: Elaborado pelos autores a partir de dados de Anatel-SICI.

Gráfico 2

Evolução da distribuição dos acessos de Banda Larga por faixa de velocidade de transmissão de dados. Dados até o $3^{\circ}$ trimestre de 2010

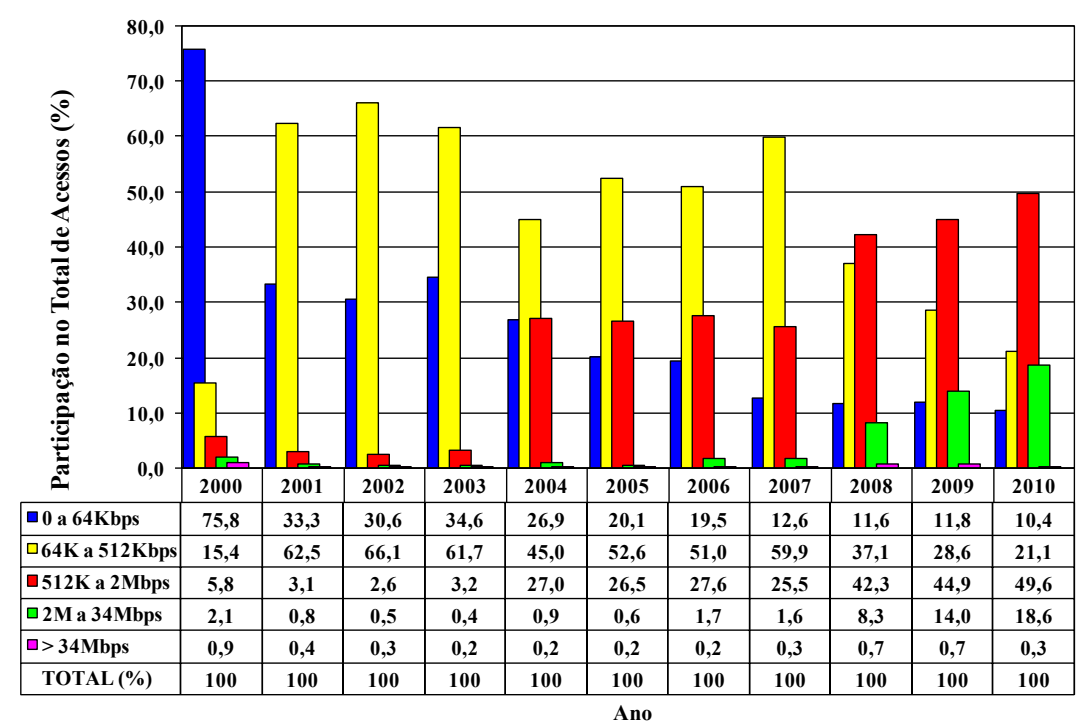

Fonte: Elaboração dos autores a partir de dados de Anatel-SICI. 
Análise de possíveis determinantes da penetração do serviço de acesso à internet em banda larga...

Gráfico 3

Evolução da participação de mercado por tecnologia dos acessos de Banda Larga. Dados até o final do $3^{\circ}$ trimestre de 2010

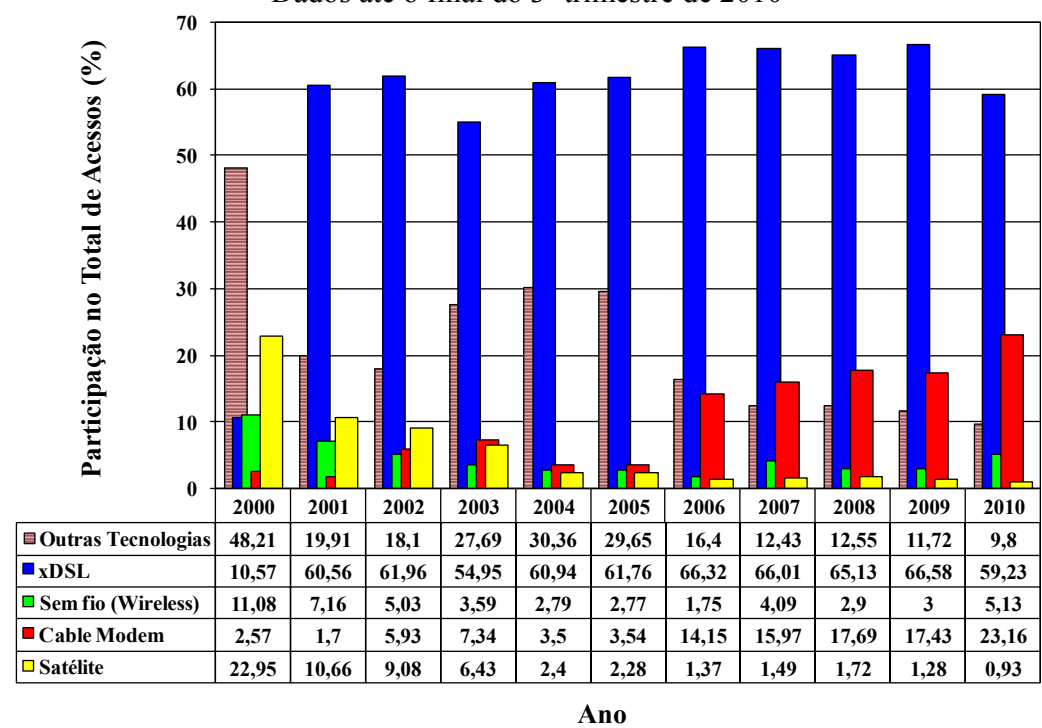

Fonte: elaborado pelos autores a partir de dados de Anatel-SICI.

No Gráfico 2 percebe-se que, com o tempo e a redução nos preços, há uma migração dos acessos de menor velocidade para os acessos mais velozes. No Gráfico 3 percebe-se que cerca de 60\% dos acessos são das empresas de telefonia fixa que utilizam a tecnologia DSL. Assim, apesar da existência de mais de 2.300 empresas, em setembro de 2010, a maior parte dos acessos fica concentrada em um pequeno grupo delas. Em segundo lugar, estão as empresas de TV a cabo, que fornecem Banda Larga com tecnologia cable modem com cerca de $20 \%$ do mercado.

Estas empresas têm um potencial de competição em relação às de telefona fixa no mercado de Banda Larga, por oferecerem em uma mesma rede de cabos metálicos, ou de fibras ópticas, serviços de TV por assinatura, Banda Larga e telefonia fixa, obtendo economia de escopo.

Dados de Anatel (2011) indicam que em 2010 houve crescimento de cerca de 30\% no número de assinantes de TV por assinatura, sendo $60 \%$ destes de TV a cabo. Um estudo de Coutinho e Oliveira (2010, p. 52) avaliando o impacto econômico da Banda Larga no país mostra que cada 1p.p. de crescimento na penetração de assinantes de TV a cabo está relacionado com 0,8p.p. de crescimento da penetração de Banda Larga.

No estudo de Baigorri, Botelho e Henriksen (2011, p. 35), identificou-se que, nos municípios onde há disponibilidade do serviço de TV a cabo (cerca de 270 municípios no país, segundo os autores, na p. 29), o número de acessos de Banda Larga é cerca de $35 \%$ superior aos municípios sem o serviço. Isto por a tecnologia 
cable modem apresentar grande potencial de concorrência em relação às prestadoras de Banda Larga via tecnologia DSL.

Assim, incentivos à ampliação da cobertura das redes de TV a cabo (que atualmente se concentram nas grandes cidades), levando o serviço às cidades menores, poderiam ser algumas das ações a serem tomadas para aumentar a penetração da Banda Larga no país.

Tabela 1

Penetração do serviço de Banda Larga, ao final de 2008 em alguns países

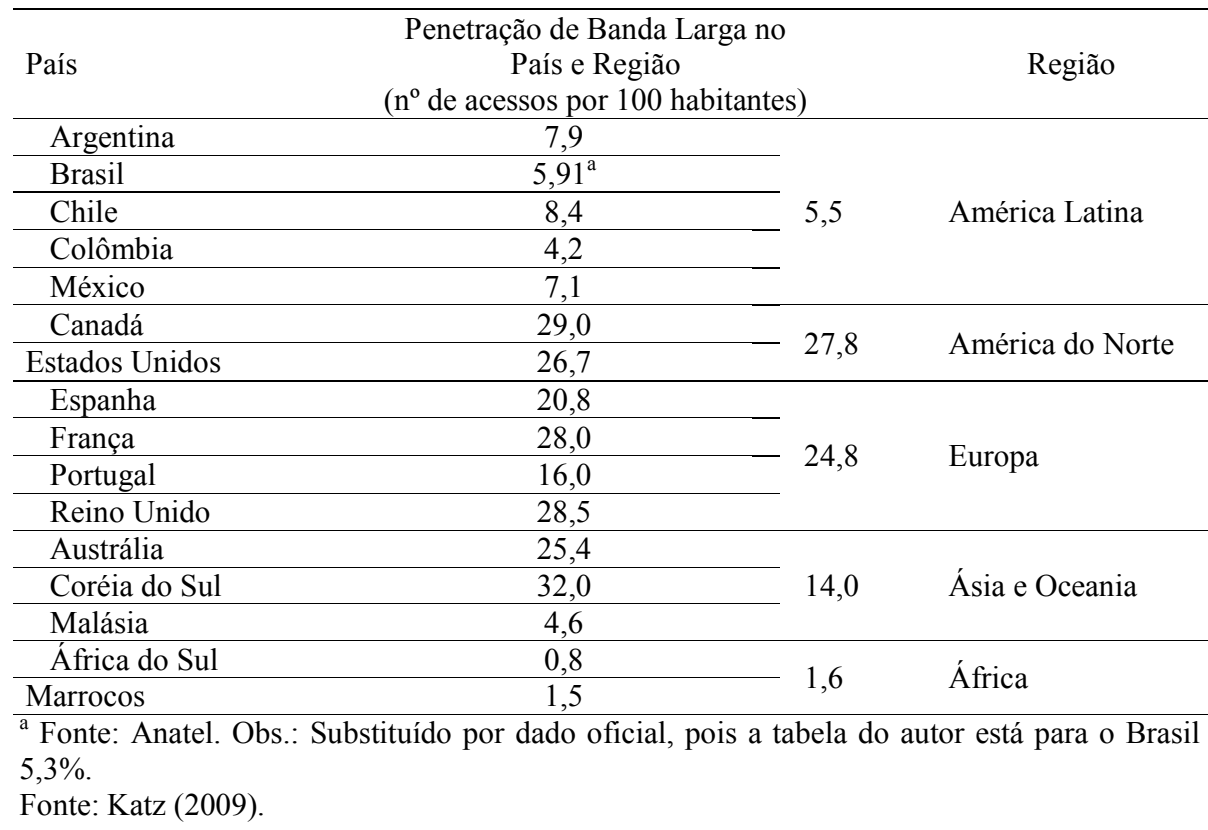

Gráfico 4

Histograma da distribuição das amostras (municípios) com valores de densidade de acessos de Banda Larga por mil habitantes em cada município em 2007

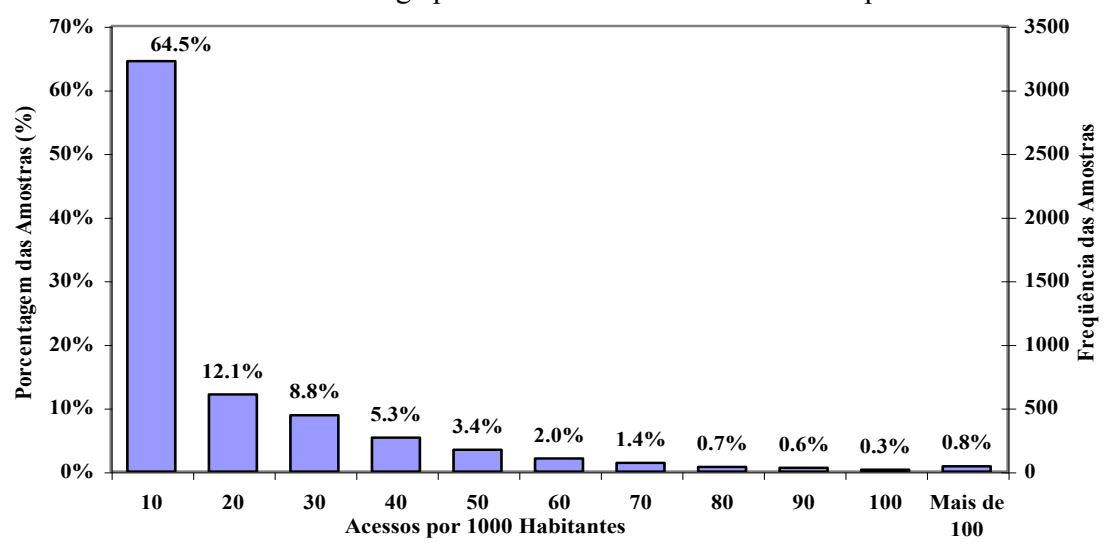

Fonte: Elaborado pelos autores a partir de dados de Anatel-SICI. 
No Apêndice (Tabela B.1) vê-se que a densidade de acessos de Banda Larga por mil habitantes em cada município tem uma variação bem grande, com mínimo de 0,032 e máximo de 524,5 acessos por mil habitantes. A média por município foi de 12,9 acessos por mil habitantes, bem abaixo da média do país em 2007 (45,8 acessos por mil habitantes) e da média do país em 2008 (59,1 acessos por mil habitantes), como apresentado na Tabela 1.

No Gráfico 4, vê-se que cerca de 64\% dos municípios tem densidades de até 10 acessos por mil habitantes (ou 1 acesso por 100 habitantes) o que é bastante baixo, próximo a países como África do Sul (com 0,8 acessos por 100 habitantes) e Marrocos (com 1,5 acessos por 100 habitantes), conforme a Tabela 1.

Também os Gráficos 5 e 6, juntamente com a Figura 1, permitem visualizar como os acessos de Banda Larga estão concentrados principalmente nas grandes cidades, enquanto que, nos municípios menos populosos, a penetração é baixa.

No Gráfico 5, vê-se que 45,97\% dos municípios têm até 10 mil habitantes mas estes contam com somente $2,24 \%$ dos acessos. No extremo oposto, as cidades com pelo menos 500 mil habitantes, apenas $0,66 \%$ dos municípios, concentram $58,41 \%$ dos acessos.

No Gráfico 6, é mostrado que os municípios com pelo menos 500 mil habitantes concentram $29,16 \%$ da população do país, mas nestes estão $58,41 \%$ dos acessos de Banda Larga, havendo uma desproporção entre o tamanho da população nestes e seu número de acesso de Banda Larga.

\section{Gráfico 5}

Distribuição das porcentagens de acesso de Banda Larga por tamanho (população) de município

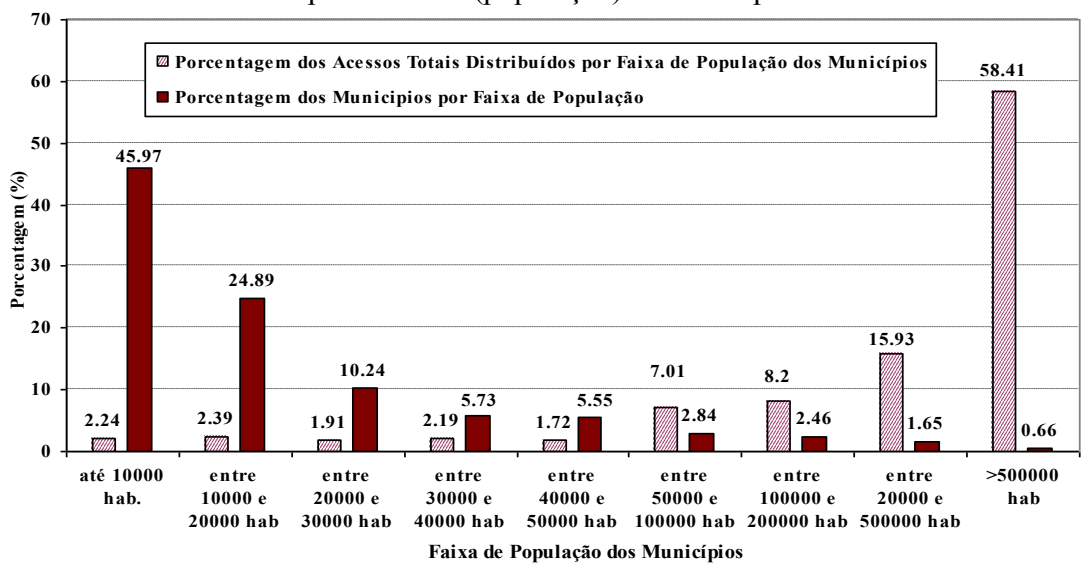

Fonte: Elaborado a partir de dados da Anatel. Distribuição da porcentagem dos municípios por faixa da população.

Fonte: Elaborado pelos autores a partir de dados de Anatel-SICI e IBGE. 


\section{Gráfico 6}

Distribuição das porcentagens de acesso de Banda Larga por tamanho (população) de município

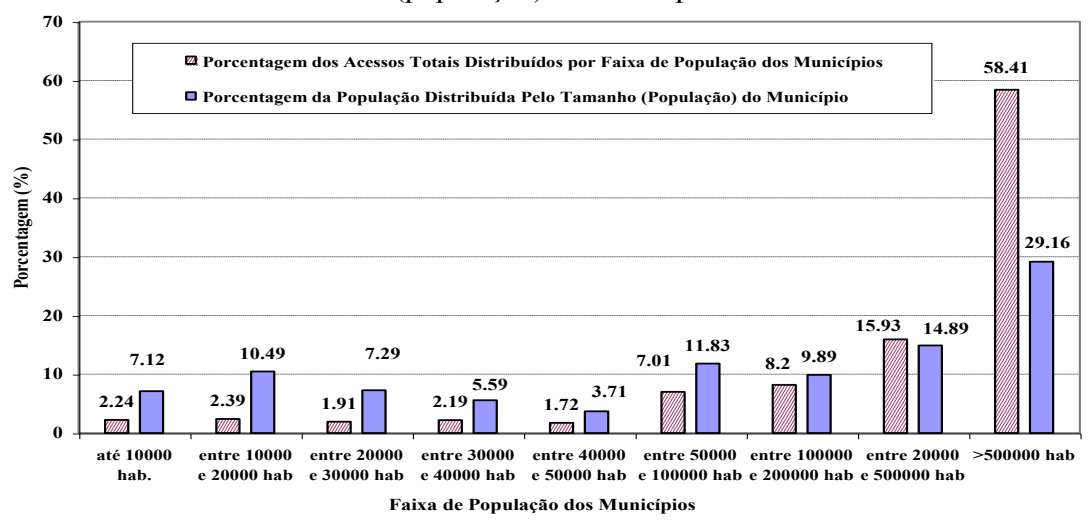

Fonte: Elaborado pelos autores a partir de dados de Anatel-SICI e IBGE.

\subsection{Concentração do mercado de Banda Larga}

Em nível municipal. o mercado de Banda Larga é bastante concentrado. No Gráfico 7 vê-se que $73,7 \%$ dos municípios contam com até 4 empresas prestando o serviço.

\section{Gráfico 7}

Histograma com distribuição do número de prestadoras de Banda Larga entre os municípios brasileiros, em 2007

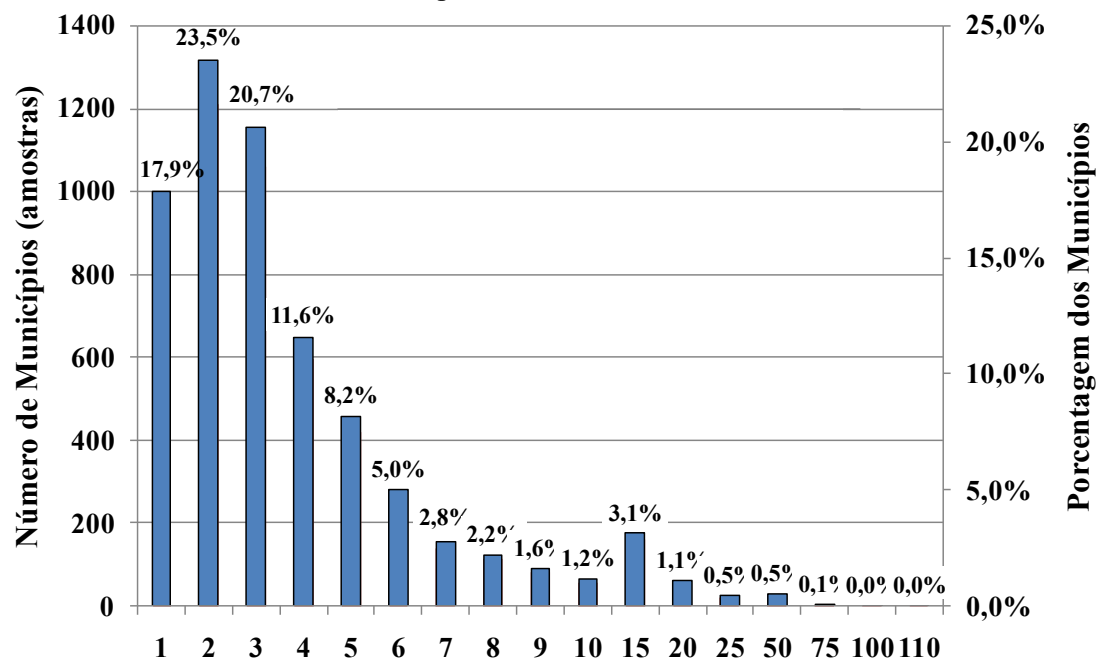

Fonte: Elaborado pelos autores a partir de dados de Anatel-SICI.

O número de prestadoras do serviço de Banda Larga em atuação no município, por si só, não expressa o real grau de concentração do mercado. Por 
Análise de possíveis determinantes da penetração do serviço de acesso à internet em banda larga...

exemplo, se existissem três empresas competindo no mesmo mercado, mas com apenas uma detendo $98 \%$ do mercado e as outras duas com apenas $1 \%$ cada, na prática seria como se houvesse um monopólio.

\section{Gráfico 8}

Histograma com a distribuição do Índice Herfindahl-Hirschman - HHI referente ao grau de competição entre empresas e entre tecnologias, nos municípios, em 2007

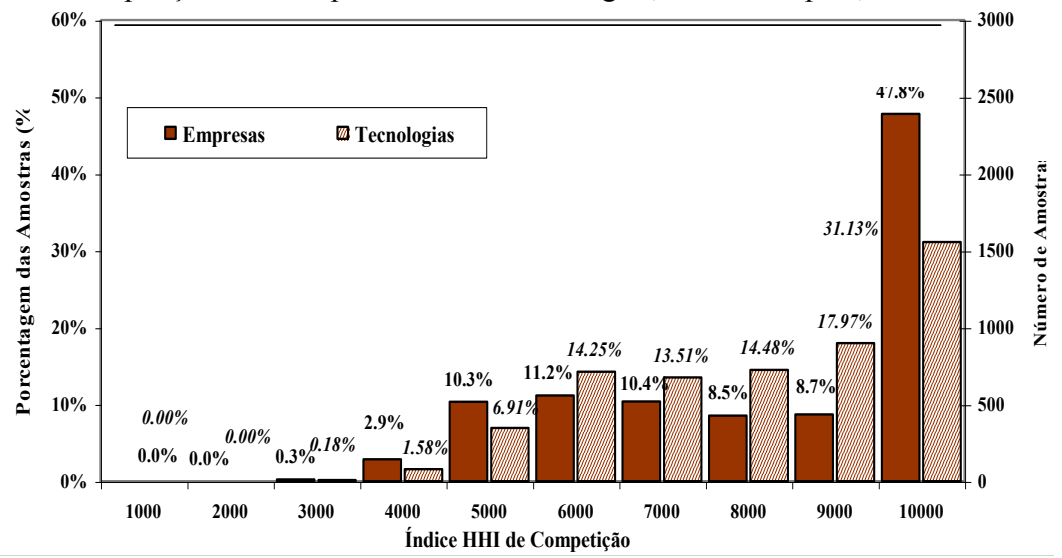

Fonte: Elaborado pelos autores a partir de dados de Anatel-SICI.

Para levar em conta isso, além do número de prestadoras, foi calculado para cada município o índice de concentração de mercado HHI - Índice HerfindahlHirschman, como descrito em Hirschman (1964) tanto em relação à competição entre empresas, como em relação às tecnologias utilizadas na prestação do serviço. $\mathrm{O}$ índice é calculado como $H H I=\sum_{i=1}^{N} S_{i}^{2}$, onde existem $\mathrm{N}$ empresas (ou tecnologias) competindo no mesmo mercado, cada uma possuindo $\mathrm{S} \%$ de fatia do mercado. Calculando para diversas combinações, têm-se os valores na Tabela 2.

Assim, quanto maior o valor de HHI, mais concentrado é o mercado, seja em relação à competição entre empresas ou entre tecnologias.

Tabela 2

Cálculo do Índice Herfindahl-Hirschman - HHI, de concentração de mercado para diversas situações

\begin{tabular}{c|c|c}
\hline $\begin{array}{c}\text { N } \\
\text { (Número de Empresas) }\end{array}$ & $\begin{array}{c}\text { S (\%) (Participação de Mercado } \\
\text { de Cada Empresa) }\end{array}$ & $\begin{array}{c}\text { HHI (Índice Herfindahl-Hirschman de } \\
\text { Concentração de Mercado) }\end{array}$ \\
\hline 1 & 100 & 10000 \\
\hline 2 & 50 & 5000 \\
\hline 3 & 33 & 3333 \\
\hline 4 & 25 & 2500 \\
\hline 5 & 20 & 2000 \\
\hline 10 & 10 & 1000 \\
\hline
\end{tabular}

Fonte: Elaborado pelos autores. 


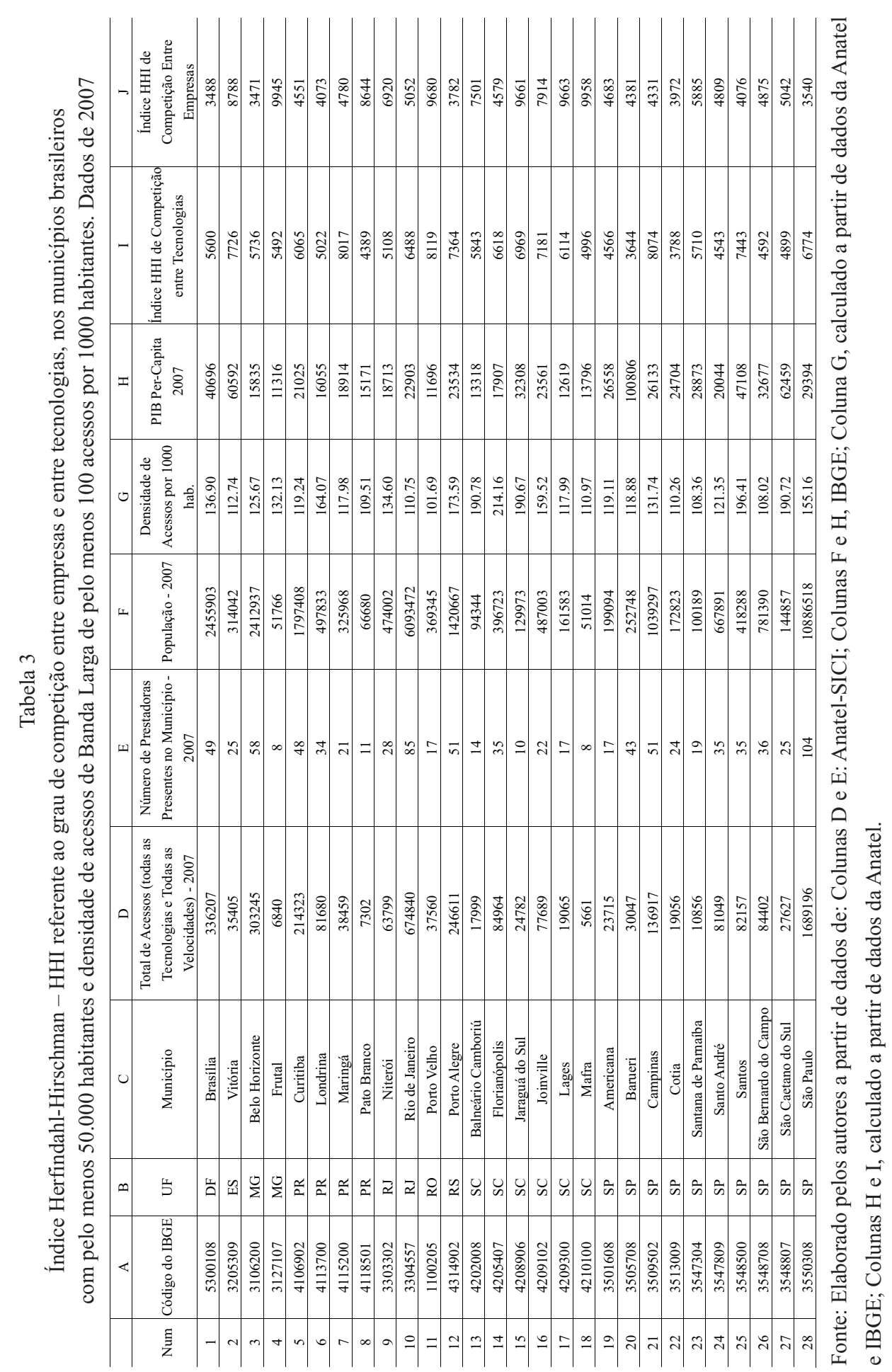


A atuação de poucas empresas em um mesmo mercado por si pode não caracterizar falta de competição. No setor de telecomunicações, devido à necessidade de altos investimentos em infra-estrutura para se obter ganhos de escala, em geral observam-se mercados relativamente concentrados.

Em Hazlett e Weisman (2011), os autores analisaram o concentrado mercado de Banda Larga norte americano, mas não encontraram evidências de que os provedores detinham poder de mercado. Isso porque não constatou-se a existência de rentabilidades excessivas por parte destas empresas, o que seria requerido para que pudessem fazer face aos grandes investimentos necessários para manter e expandir suas redes.

Mesmo em cidades com grande número de prestadoras de Banda Larga, seja para o mercado empresarial ou para o residencial como São Paulo/SP (que, segundo os dados da Anatel reproduzidos parcialmente na Tabela 3, em 2007, teria a presença de 104 empresas ofertando o serviço), a concentração é elevada. Neste exemplo, o índice HHI de concentração era de 3.540 em 2007. Nesta tabela, foram agrupados os dados das cidades com pelo menos 50.000 habitantes e penetração de pelo menos 100 acessos de Banda Larga por 1.000 habitantes.

No histograma do Gráfico 8, o índice HHI de concentração para empresas é bem elevado, próximo do monopólio total $(\mathrm{HHI}=10.000)$. Quase metade das amostras (municípios) apresenta situação de monopólio na prestação do serviço de Banda Larga. Na Tabela B.1, vê-se que o menor valor de HHI para empresas foi de 2.330, o que seria equivalente a algo como 4 ou 5 empresas com fatias de mercado semelhantes, conforme a Tabela 2 .

No Gráfico 9, é apresentado um histograma com os índices IHH de concentração referentes a empresas e tecnologias e desagregado por tamanho da população dos municípios. Os municípios menores, com até 10.000 habitantes são os mais prejudicados pela falta de competição, resultando na media, para estes municípios, de um HHI de 8445.

O Gráfico 10 apresenta informações sobre índice HHI de acordo com a densidade de acessos de Banda Larga por município.

Nos Gráficos 8, 9 e 19 vêem-se que em geral os índices de concentração HHI referentes à competição entre tecnologias são menores que os respectivos valores relativos entre a competição entre empresas. 


\section{Gráfico 9}

Histograma com a distribuição do Índice Herfindahl-Hirschman - HHI referente ao grau de competição entre empresas e entre tecnologias, por faixa de população dos municípios, em 2007

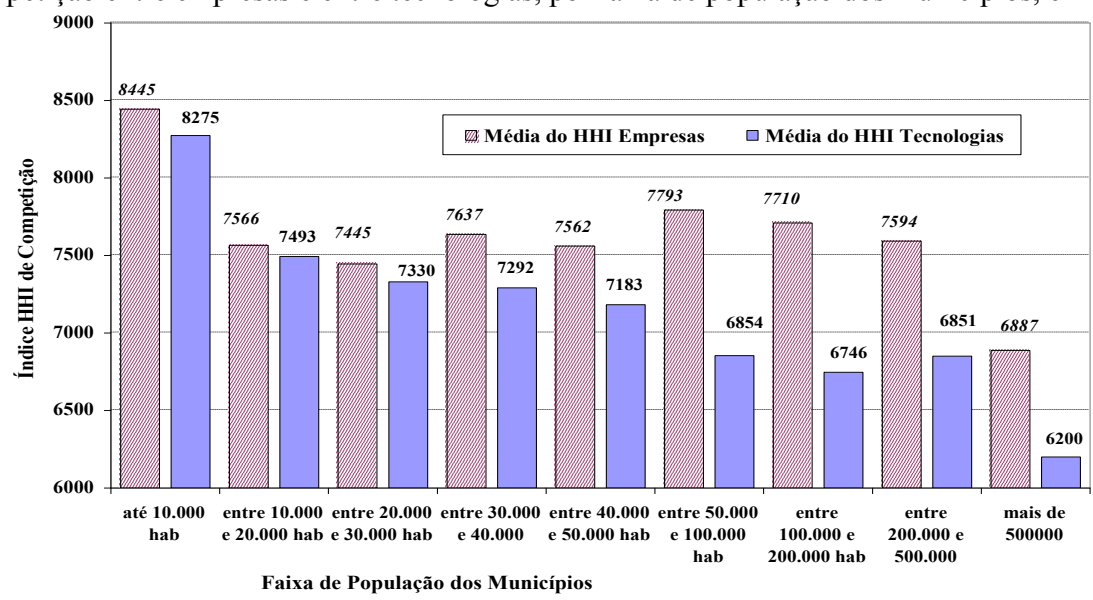

Fonte: Elaborado pelos autores a partir de dados de Anatel-SICI e IBGE.

\section{Gráfico10}

Histograma com a distribuição do Índice Herfindahl-Hirschman - HHI referente ao grau de competição entre empresas e entre tecnologias, por faixa de penetração do serviço de Banda Larga (densidade de acessos por 1000 habitantes) nos municípios, em 2007

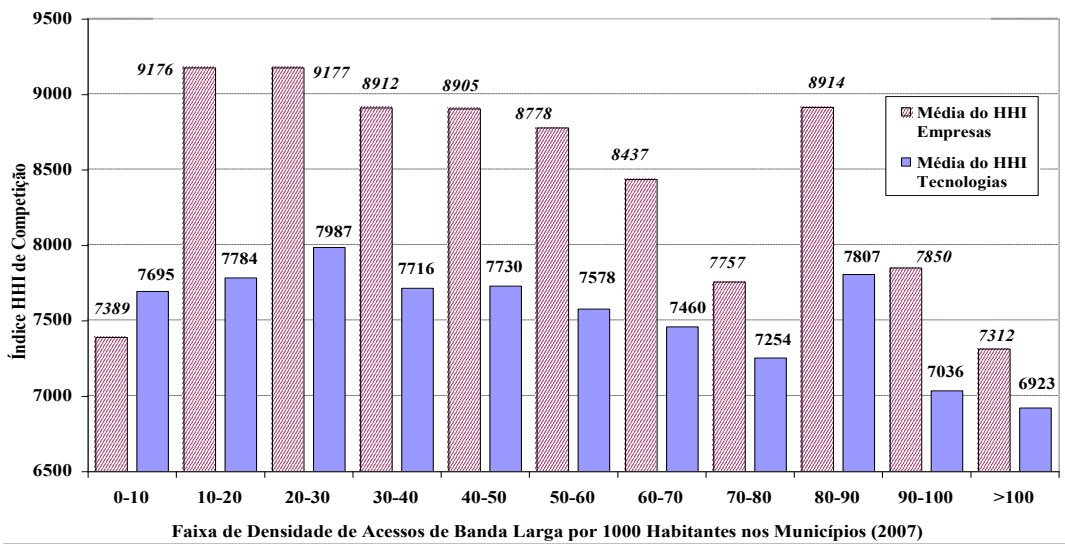

Fonte: Elaborado pelos autores a partir de dados de Anatel-SICI.

O nível de renda na maior parte do país é baixo. A maior parte dos municípios tem população reduzida, com menos de 50 mil habitantes, representando mercados com menor número de clientes em potencial. A dispersão geográfica destes municípios menores em um país de grandes dimensões como o Brasil eleva o custo de se levar a infra-estrutura necessária (o backhaul) à prestação de Banda Larga devido às grandes distâncias a serem percorridas. Obstáculos 
naturais, como há, por exemplo, na Região Norte do país, também aumentam estes custos de implantação. Assim, esta conjunção de fatores acaba por afastar os investimentos na ampliação da infra-estrutura necessária para a oferta do serviço de Banda Larga nas cidades menores.

\section{Descrição do modelo}

Os motivos da escolha de modelos de regressão cross-section para as análises foram:

- Fazer-se uma análise mais qualitativa que quantitativa dos fatores relacionados com a penetração de Banda Larga no Brasil. Por isso, foi adotada uma abordagem mais descritiva, conforme detalhado em Carvalho e Albuquerque (2010) e Holmes (2010). Neste tipo de abordagem, o objetivo não é o de tentar estabelecer relação de causalidade entre variáveis ou mesmo de quantificar o impacto da variação de uma sobre a outra. As preocupações principais são quanto ao sinal de cada coeficiente da variável, positivo ou negativo, indicando uma relação positiva ou negativa entre variáveis, e também quanto ao grau de significância dessas variáveis, ou seja, se há um relacionamento estatisticamente consistente entre elas.

Se a intenção é a de se tentar quantificar os impactos de cada fator sobre a penetração de Banda Larga, seria mais adequada uma abordagem estruturalista, com uso de equações simultâneas, ou experimentalista, com uso de análise de dados em painel.

- Tanto a indisponibilidade de séries históricas de dados desagregados (por município ou por Estado) do número de acessos de Banda Larga com as respectivas fatias de mercado de cada empresa usadas para compor o HHI, quanto a indisponibilidade dos indicadores de desenvolvimento humano (IFDM) inviabilizaram a análise de dados em painel ou equações simultâneas.

A metodologia empregada é similar à utilizada por Lee e Brown (2008).

Apesar das limitações metodológicas, ainda assim o estudo permite trazer à luz alguns aspectos relativos ao setor de Banda Larga no Brasil não abordados em trabalhos anteriores, em particular quanto ao grau de competição no setor ao nível dos municípios. Tal análise pode servir de subsídio para elaboração de políticas de ampliação da penetração de Banda Larga no país.

Nosso objetivo foi o de utilizar para as variáveis explicativas indicadores simples. Por isso, por exemplo, o uso do número de prestadoras do serviço de Banda Larga presentes no município como um indicador simplificado que traga 
consigo alguma informação sobre a existência, ainda que de forma precária, de competição entre empresas em nível municipal. Entretanto isto foi complementado calculando-se o índice de concentração de mercado, em cada município com o uso do Índice Herfindahl-Hirschman (HHI), conforme descrição apresentada em outra seção.

A análise se limitou aos dados de indicadores disponíveis, assim importantes fatores que afetam a demanda pelo serviço, como o preço, por exemplo, não puderam ser incluídos.

Foram utilizados oito modelos de regressão combinando diferentes variáveis explicativas.

O Modelo 1 incluiu o número de prestadoras de Banda Larga como indicador de competição, que foi substituído no Modelo 2 e Modelo 3 pelo HHI referente a competição entre empresas e tecnologias. No Modelo 4, incluíram-se todas as variáveis disponíveis para verificar como se daria a interação entre todas. No Modelo 5, incluíram-se todas as variáveis menos o número de prestadoras por variável contemplada nos índices HHI das empresas e das tecnologias. O Modelo 6 é o mesmo que o 5, mas com somente municípios com pelo menos 50.000 habitante incluídos. O objetivo foi o de avaliar se haveria diferenças nos resultados se fossem analisadas somente as cidades maiores, que tem um perfil diferente das cidades menores quanto à maior atividade econômica, maior concentração populacional, maior nível de riqueza total entre outros fatores. No Modelo 7, houve inversão, incluindo-se os municípios menores, com até 50.000 habitantes. No Modelo 8, excluiu-se o indicador de desenvolvimento humano referente a emprego e renda, pois nos modelos anteriores não apresentou significância relevante quando combinada com as variáveis relativas ao nível de competição de empresas e tecnologias (HHI).

Como o PIB per capta é também um indicador do nível de riqueza do município, mas não de nível de emprego, e de certa maneira poderia substituir a variável do indicador IFDM de emprego e renda, esta última variável foi excluída neste modelo.

\section{Descrição das variáveis}

As variáveis explicativas utilizadas nos modelos são descritas no Quadro 1: 
Análise de possíveis determinantes da penetração do serviço de acesso à internet em banda larga...

Quadro 1

Descrição das variáveis explicativas

\begin{tabular}{|c|c|c|}
\hline $\begin{array}{c}\text { Variável } \\
\text { Explicativa }\end{array}$ & Sigla & Descrição \\
\hline $\mathrm{x}_{0}$ & $\mathrm{C}$ & Constante. \\
\hline $\mathrm{x}_{1}$ & FRACAO_PIB_AGRO_2007 & \multirow{3}{*}{$\begin{array}{l}\text { Frações do PIB Municipal, em } 2007 \text {, } \\
\text { decorrentes de atividades dos setores } \\
\text { agropecuário, industrial e de serviços. Fonte, } \\
\text { calculados a partir de dados do IBGE. }\end{array}$} \\
\hline $\mathrm{x}_{2}$ & FRACAO_PIB_IND_2007 & \\
\hline $\mathrm{x}_{3}$ & FRACAO_PIB_SERV_2007 & \\
\hline $\mathrm{x}_{4}$ & IFDM_EDU_2005 & \multirow{3}{*}{$\begin{array}{l}\text { Índice Firjan de Desenvolvimento Municipal } \\
\text { (IFDM) referentes aos ítens: Educação, } \\
\text { Emprego e Renda e Saúde no ano de } 2005 . \\
\text { Fontes FIRJAN e IPEA. }\end{array}$} \\
\hline $\mathrm{x}_{5}$ & IFDM_EMPREGO_2005 & \\
\hline $\mathrm{x}_{6}$ & IFDM_SAUDE_2005 & \\
\hline $\mathrm{x}_{7}$ & NUM_PRESTADORAS & $\begin{array}{l}\text { Número de empresas de telecomunicações } \\
\text { ofertando o serviço acesso à internet em Banda } \\
\text { Larga presentes no município em 2007. Fonte: } \\
\text { Anatel. }\end{array}$ \\
\hline $\mathrm{x}_{8}$ & PIB_PER_CAPITA_2007 & $\begin{array}{l}\text { PIB per capita do município, em 2007. Fonte: } \\
\text { IBGE. }\end{array}$ \\
\hline $\mathrm{x}_{9}$ & POP_2007 & $\begin{array}{l}\text { População do município. Estimativa para o ano } \\
\text { de } 2007 \text {. Fonte IBGE, tabela } 793 \text {, população } \\
\text { residente. }\end{array}$ \\
\hline $\mathrm{x}_{11}$ & HHI_TECNOLOGIAS & $\begin{array}{l}\text { Índice Herfindahl-Hirschman }(\mathrm{HHI}) \text { de } \\
\text { concentração do mercado, relativo à } \\
\text { competição entre tecnologias de prestação do } \\
\text { acesso à internet em Banda Larga e entre } \\
\text { empresas prestadoras do serviço. Fonte: } \\
\text { calculado a partir de dados da Anatel. }\end{array}$ \\
\hline
\end{tabular}

Fonte: Elaborado pelos autores.

\subsection{Modelo de Regressão}

a) Base de dados: todas as cidades com dados disponíveis (5.135 municípios).

b) Variável dependente: $\ln \left(\mathbf{y}_{1}\right)$ : logaritmo natural do $\mathrm{n}^{\mathrm{o}}$ de acessos por 1.000 habitantes no município:

$$
\ln \left(y_{1}\right)=\ln \left(\frac{\text { totalde acessos de banda larga no município }}{n^{0} \text { de habitantesdo município }}\right),(\text { Eq. 1) }
$$

c) Modelo:

$y_{1}=\beta_{0} \cdot x_{1}^{\beta_{1}} \cdot x_{2}^{\beta_{2}} \cdot x_{3}^{\beta_{3}} \cdot x_{4}^{\beta_{4}} \cdot x_{5}^{\beta_{5}} \cdot x_{6}^{\beta_{6}} \cdot x_{7}^{\beta_{7}} \cdot x_{8}^{\beta_{8}} \cdot x_{9}^{\beta_{9}} \cdot x_{10}^{\beta_{10}} \cdot x_{11}^{\beta_{11}}$, (Eq. 2)

Modelo linearizado: 


$$
\begin{aligned}
\ln \left(y_{1}\right)= & \ln \left(\beta_{0}\right)+\beta_{1} \cdot \ln \left(x_{1}\right)+\beta_{2} \cdot \ln \left(x_{2}\right)+\beta_{3} \cdot \ln \left(x_{3}\right)+\beta_{4} \cdot \ln \left(x_{4}\right)+\beta_{5} \cdot \ln \left(x_{5}\right) \ldots \\
& \ldots+\beta_{6} \cdot \ln \left(x_{6}\right)+\beta_{7} \cdot \ln \left(x_{7}\right)+\beta_{8} \cdot \ln \left(x_{8}\right)+\beta_{9} \cdot \ln \left(x_{9}\right)+\beta_{10} \cdot \ln \left(x_{10}\right)+\beta_{11} \cdot \ln \left(x_{11}\right)
\end{aligned},
$$

d) Método de regressão: GMM, Método dos Momentos Generalizado, com uso de variáveis instrumentais com correção de heterocedasticidade de NeweyWest e OLS (Ordinary Least Squares), mínimos quadrados ordinários também com correção robusta de Newey-West para a heterocedasticidade

e) Variáveis instrumentais: em cada um dos modelos, todas as variáveis explicativas utilizadas foram também empregadas como variáveis instrumentais. Assim como em cada modelo foi utilizado um conjunto diferente de variáveis, cada conjunto de variáveis, específico de modelo, foi replicado como variável instrumental. Além disso, as regressões em GMM incluíram o PIB per capita como regressor endógeno, sendo utilizadas também como variáveis instrumentais o PIB per capita e a população dos municípios em 2006.

f) Aplicou-se o teste de Hausman para verificar a possível existência de endogeneidade. O teste compara as diferenças entre os coeficientes obtidos por regressão com variáveis instrumentais e obtidos por mínimos quadrados ordinários (OLS). A hipótese nula (H0) é a de que não há diferenças sistemáticas dos valores dos coeficientes entre os dois métodos de regressão. No caso, a hipótese nula não foi rejeitada em nenhum dos modelos, conforme resultados da Tabela A.1, indicando que os modelos não apresentam endogeneidade.

\section{Descrição dos dados}

\subsection{Número de acessos por município e número de prestadoras}

Os dados dos números de acessos de Banda Larga por município e o de prestadoras provêm da Anatel. Esta os coleta junto às prestadoras, através do sistema SICI - Sistema de Coleta de Informações. Apenas os dados a partir de 2007 têm o detalhamento ao nível de município. Para os anos anteriores, de 2000 a 2006, estão disponíveis dados consolidados para o país inteiro.

Do total de 5.565 municípios do país, somente 5.137 contavam com acessos de Banda Larga em 2007, de acordo com os dados da Anatel. No caso, são considerados como acessos de banda larga aqueles do Serviço de Comunicação Multimídia - SCM, e de outros serviços equivalentes, de acordo com os dados públicos da Anatel. Vale lembrar que esta empresa classifica os acessos de banda larga (SCM) pelas faixas de velocidade de transmissão: de 0kbps a 64kbps, de $64 \mathrm{kbps}$ a $512 \mathrm{kbps}$, de $512 \mathrm{kbps}$ a $2 \mathrm{Mbps}$, de $2 \mathrm{Mbps}$ a $34 \mathrm{Mbps}$ e acima de $34 \mathrm{Mbps}$, sendo considerados os acessos em todas estas faixas de velocidade. 
Análise de possíveis determinantes da penetração do serviço de acesso à internet em banda larga...

\subsection{PIB municipal per capita e distribuição do PIB municipal entre os setores agropecuário, industrial e de serviços}

Os dados referentes ao PIB em nível municipal provêm do IBGE, que os desagrega nas parcelas decorrentes de atividades do setores agropecuário, industrial e de serviços. Ele também inclui a parcela decorrente de gastos do poder público, mas estes dados não foram incluídos nos modelos.

\section{3 Índice FIRJAN de desenvolvimento municipal}

O objetivo do modelo foi o de tentar relacionar a penetração de Banda Larga nos municípios com seus indicadores de desenvolvimento econômico e humano.

Os dados relativos ao PIB per capta municipal serviram para quantificar em parte o nível de desenvolvimento econômico.

$\mathrm{O}$ indicador de desenvolvimento humano utilizado, IFDM, foi elaborado pela Firjan - Federação das Indústrias do Estado do Rio de Janeiro referente ao ano de 2005 (o anterior a este é de 2000). Ele é composto por uma síntese de diversos indicadores sociais nas áreas da saúde, educação e emprego e renda, que resultam em um valor entre 0 e 1 ( 0 é o pior e 1, o melhor), atribuído para cada município nestes três quesitos. Dos 5.137 municípios com acessos de Banda Larga, de acordo com dados da Anatel, sobre 2 destes não havia dados de indicador de desenvolvimento humano da Firjan. Assim, a amostra final contou com 5.135 municípios.

Há dificuldades de se encontrar indicadores recentes de desenvolvimento humano desagregados ao nível de município. O que se encontra comumente está agrupado por regiões ou estados. A opção por utilizar este indicador de desenvolvimento humano foi devido à sua pronta disponibilidade, grande abrangência (cobrindo quase todos os municípios do Brasil) e por ser relativamente recente (dados de 2005).

\section{4 Índice Herfindahl-Hirschman-HHI, referente ao grau de competição entre empresas e tecnologias}

O uso deste índice de concentração de mercado já foi usado em outros estudos para o setor de telecomunicações. Em Koutroumpis (2009, p. 476), que estudou o impacto econômico trazido pela Banda Larga, foi utilizado como indicador de competição entre tecnologias.

Há também outros índices, como o C4 (fatia de mercado detida pelas quatro maiores empresas), utilizado no estudo Ipea (2010), que fez uma análise do setor de Banda Larga no Brasil, propondo ações para sua massificação. Entretanto, 
preferiu-se optar pelo HHI, pois, no Gráfico 7, cerca de 73,7\% dos municípios possuem até 4 prestadoras de Banda Larga, segundo os dados da Anatel de 2007. Se o C4 fosse utilizado, a maior parte das amostras apresentaria valor igual a $100 \%$ tornando mais difícil estabelecer uma relação entre concentração de mercado e penetração de Banda Larga. O HHI, por apresentar maior diversidade de valores, talvez fosse um indicador mais adequado para a presente análise.

O motivo de se utilizar um indicador de competição entre tecnologias é o conhecimento de que as empresas de telefonia fixa, ao herdarem as extensas redes de telefonia após a privatização destas, contam com uma grande vantagem competitiva em relação a possíveis novos entrantes no mercado.

O custo de se implantar novas redes de cabos para prover o serviço de Banda Larga é bastante elevado seja para uso de tecnologia DSL ou para fibras ópticas. Assim, a opção utilizada por estes novos competidores tem sido o uso de tecnologias alternativas ao DSL, por exemplo, o uso de redes de acesso sem fio, através de radiofrequências com tecnologias como WiFi, WiMax, 3G (telefonia celular de terceira geração) e outros meios, oferecendo vantagens como a mobilidade.

\section{Apresentação dos Resultados}

$\mathrm{Na}$ Tabela A,1, são apresentados os valores dos coeficientes de regressão de todos os modelos utilizados na análise do tema. A partir da análise destes, podem ser feitos alguns comentários.

\section{a) Alocação do PIB Municipal:}

Um dos motivadores iniciais para o estudo foi o de se tentar avaliar qual perfil econômico de cada município mais relacionado com uma maior penetração de Banda Larga. A expectativa era a de que, em municípios com maior parcela de seu PIB vindos de atividades dos setores industrial e de serviços, haveria maior favorecimento ao aumento da penetração do serviço. Em particular, era esperado que o setor de serviços tivesse o peso maior de vinculação com o aumento da penetração do serviço, pela sua maior dinâmica em relação aos outros setores.

Isso ficou evidente em todos os modelos. Na Tabela A.1, pelos valores dos coeficientes das variáveis de parcela do PIB municipal vindo dos setores agropecuário, industrial e serviços, vê-se que, em ordem decrescente de importância, tem-se o setor de serviços, seguido pelo setor industrial e por último pelo setor agropecuário, na vinculação com o aumento de penetração do serviço.

Comparando os valores dos coeficientes entre si, observa-se que o setor de serviços tem um peso cerca de dez vezes maior que o setor agropecuário no impacto sobre o aumento da densidade de acessos de Banda Larga nos municípios. 
Análise de possíveis determinantes da penetração do serviço de acesso à internet em banda larga...

\section{b) Indicadores de desenvolvimento em educação, emprego e renda, e saúde}

Outro dos objetivos iniciais era o de obter indícios de qual dos indicadores de desenvolvimento humano dentre as áreas de educação, emprego e renda e saúde seria mais relacionado com a penetração de Banda Larga nos municípios. Esperava-se, inicialmente, maior influência dos indicadores de educação e emprego e renda, ficando o de saúde com um peso menor. Isto talvez tenha ocorrido pelo peso maior das variáveis referentes ao nível de competição, que tornaram a variável referente ao emprego e renda de menor impacto, no modelo.

Porém, os resultados na Tabela A.1 indicaram outro cenário. O indicador relativo à saúde foi o que apresentou maior influência em todos os modelos. $\mathrm{O}$ de educação sempre apareceu em segundo, mas com valores de coeficientes bem próximos aos do indicador de desenvolvimento na área de saúde. E, por último, contrariando a expectativa, vem o indicador de nível de emprego e renda no município. Este não apenas apresentou valores reduzidos de seus coeficientes, como também, em alguns modelos (com a presença de outras variáveis, como as referentes ao grau de competição entre empresas e tecnologias), apresentou baixas significâncias indicando que a variável nem mesmo seria relevante para explicar a variável dependente.

Pode-se tentar explicar esta inversão na importância dos três fatores sobre a variável dependentes, imaginando-se que na prática o indicador relativo à saúde, pela forma como é construído, traria embutido dentro de si aspectos que dariam uma radiografia mais fiel no nível geral de desenvolvimento humano do município.

Também verificou-se correlação relativamente elevada entre as variáveis IFDM_SAUDE_2005 e IFDM_EDU_2005 como visto na Tabela A.1., tendo valor de 0,692. Assim, talvez o indicador de desenvolvimento humano na área da saúde tenha embutido em si a parcela referente ao indicador de desenvolvimento na área de educação. Talvez por isso, no cômputo geral, o indicador referente ao desenvolvimento do município na área da saúde apresente o maior valor de coeficiente dentre os três indicadores de desenvolvimento humano.

A penetração do serviço de Banda Larga é bastante sensível ao seu preço (ou ao poder de compra da população). Isto é indicado por estudos, como o de Guedes et al. (2008, p.7), que obteve o valor de $-2,0$ para a elasticidade preçodemanda para o serviço de Banda Larga no Brasil, e também de Wohlers, Abdala, e Kubota (2009) e Ávila (2008, p.49), onde, neste último, a elasticidade preçodemanda encontrada variou entre -3,36 e -1,0. Em Galperin and Ruzzier (2013), o valor encontrado para o Brasil foi de $-2,16$ e a média para a América Latina e Caribe foi de $-2,20$. 
Por não haver disponibilidade de dados dos preços praticados, em nível municipal, não foi possível a inclusão desta importante variável nos modelos.

Como a variável de PIB per capita expressa de alguma forma também o nível de riqueza do município, poderia, assim, em parte, compensar o desempenho não esperado da variável do indicador de emprego e renda (em relação à renda, mas não ao nível de emprego). Assim, no último modelo analisado, foi excluída a variável do indicador de desenvolvimento do município quanto aos itens de emprego e renda. Para cobrir em parte sua falta, foi mantido o PIB per capita.

\section{c) Grau de competição entre prestadoras e entre tecnologias na oferta de Banda Larga}

O grau de competição entre empresas e tecnologias foi quantificado calculando-se o Índice Herfindahl-Hirschman (HHI) para cada amostra (município). Os resultados atenderam parcialmente às expectativas de que quanto maior a competição (menores os valores do índice HHI), maior a penetração do serviço.

Sobre a competição entre tecnologias utilizadas na prestação do serviço de Banda Larga, como DSL, Cable Modem, WiMax, WiFi, 3G entre outras, os resultados foram consistentes ao longo de todos os modelos analisados. Foi observado sempre o sinal negativo para o coeficiente da variável de grau de concentração de mercado relativo às tecnologias, como apresentado na Tabela A.1.

Isto permite concluir que, quanto maior for a diversidade de tecnologias de prestação do serviço de Banda Larga presentes no município, há um favorecimento ao aumento da penetração do serviço.

A idéia é a de que, para novos entrantes nos mercados, é mais viável economicamente o uso de outras tecnologias que precisam de menores investimentos para competir com as empresas de telefonia fixa, que dominam o mercado com as redes herdadas da privatização, sobre as quais é bem menos custoso oferecer Banda Larga com tecnologia DSL.

Este é o caso das redes de Banda Larga sem fio, que fazem a distribuição do sinal por meio de radiofrequências, necessitando de investimentos bem menores do que as redes de cabos, DSL, para o início da oferta do serviço.

Os resultados são semelhantes aos encontrados por Lee e Brown (2008, p. 34), que destacam o impacto da competição entre tecnologias como fator que eleva a penetração do serviço. Entretanto, eles mencionam que o impacto é maior quando a fatia de mercado da tecnologia dominante é similar à soma das demais não dominantes.

Contudo, quando se procurou relacionar o grau de competição entre empresas (e não entre tecnologias) com o aumento da penetração do serviço, os resultados contrariaram as expectativas. Isto pode ser visto na Tabela A.1, que 
apresentou valores positivos para todos os coeficientes da variável de grau de concentração (índice HHI) referente às empresas. O esperado era obter sempre o sinal negativo para os coeficientes, indicando que quanto menor a concentração de mercado, e daí maior a competição, maior seria a penetração do serviço.

Uma possível explicação para o ocorrido foi apresentada no item 5.4. Na Tabela 3 e nos Gráficos 8, 9 e 10, percebe-se que, em todos os municípios do país, o grau de concentração de empresas no mercado de Banda Larga é bem elevado. $\mathrm{Na}$ Tabela B.1, vê-se que o menor valor encontrado para o índice HHI referente à competição entre empresas foi de 2.330 .

Isto fica bem evidenciado no Gráfico 10, onde é apresentado um histograma com os valores do índice HHI distribuídos pela faixa de penetração do serviço. Não aparece uma relação clara entre a diminuição do nível de concentração (valor de HHI) e o aumento da densidade de acessos de Banda Larga. Para densidades de acesso entre 10 acessos por mil habitantes até 80 acessos por mil habitantes, há uma ligeira queda do nível de concentração com o aumento da penetração. Mas o valor do índice HHI volta a subir quando a densidade de acessos passa de 80 por mil habitantes.

Embora com o uso do HHI não tenha sido possível estabelecer-se uma relação clara e direta entre a alta concentração de mercado e à baixa penetração de Banda Larga, mesmo assim, ele nos forneceu informações importantes sobre o grau de concentração do setor, permitindo o diagnóstico e a elaboração de políticas públicas, como o Plano Nacional de Banda Larga para aumentar a competição no setor.

Como mencionado anteriormente, a penetração de Banda Larga no Brasil é bastante sensível ao preço. No estudo IPEA (2010, p.7) são destacados três fatores que contribuem para o alto preço do serviço: o baixo nível de competição, a elevada carga tributária e o baixo nível de renda da população.

Deve-se sempre atentar que existem mercados concentrados bastante competitivos e, da mesma maneira, mercados menos concentrados com baixa competição. Assim, a existência de muitos competidores por si só não seria suficiente para aumentar a penetração de Banda Larga, porque o setor de telecomunicações em particular exige grandes investimentos e depende de grandes economias de escala para atuar de forma competitiva.

Como exemplo, o mercado de telefonia fixa local nos EUA é concentrado e os serviços prestados são de boa qualidade, o mesmo não se percebe no Brasil. No caso dos EUA, os baixos preços oferecidos pelas empresas de telefonia fixa servem como barreira de entrada a novos competidores no mercado de telefonia local, que teriam de fazer grandes investimentos na implantação de suas redes, mas 
correriam o risco de serem alvo de uma guerra de preços das operadoras incumbents, o que inviabilizaria a entrada de competidores.

Entretanto, como enfatiza Benkler (2009, p.75), a implementação de políticas que permitam o compartilhamento de infra-estrutura entre as operadoras de telecomunicações reduz os investimentos necessários para os novos entrantes no mercado, tendo efeito acentuado sobre o aumento da penetração da Banda Larga. Assim, está dentro do razoável no setor de Banda Larga tentar que se estabeleça esta relação entre concentração e competição, assim como o uso do indicador HHI como medida de concentração de mercado.

Talvez o uso do HHI para explicar o aumento ou diminuição da demanda fosse inadequado se a análise, por exemplo, fosse sobre a demanda por telefonia fixa ou energia elétrica (setores onde há grandes concentrações de mercado) e é bem aceito que se tratam de situações de monopólio natural, não sendo eficiente, por exemplo, várias empresas competindo no mesmo mercado, cada uma construindo sua rede própria para atendimento aos seus clientes.

Entretanto, no caso da Banda Larga, a situação se difere um pouco pelo fato de existirem diversas tecnologias alternativas que permitem a coexistência e a competição de diversas empresas no mesmo mercado. Como exemplo, temos as redes sem fio com tecnologia $\mathrm{WiFi}$, bastante utilizada por pequenos provedores de Banda Largam WiMax, ou celulares de $3^{\mathrm{a}}$ geração ( $3 \mathrm{G}$, com tecnologia WCDMA), além das redes de TV a cabo, que são concorrentes diretos das empresas de telefonia fixa que prestam o serviço de Banda Larga com o uso da tecnologia DSL.

Cada tecnologia apresenta suas vantagens e desvantagens em relação às demais. Por exemplo, o acesso em Banda Larga por meio de redes sem fio permite a mobilidade dos usuários, o que as redes DSL não permitem. Além disso, para atenderem uma mesma área geográfica atendida por redes DSL, as redes sem fio requerem menores investimentos e podem ser implantadas em menor tempo que as redes DSL, por não precisarem estender redes de cabos metálicos ou de fibras ópticas. Como desvantagens, apresentam menores taxas de transmissão de dados que as oferecidas por redes com tecnologia DSL.

Outro exemplo: as operadoras de TV a cabo são concorrentes diretas das empresas de telefonia fixa no mercado de Banda Larga, conforme mencionado anteriormente.

Dada esta diversidade de tecnologias disponíveis para a prestação de Banda Larga, há abertura para novos entrantes nestes mercados, ainda que dominados pelas empresas de telefonia fixa com a tecnologia DSL.

É neste contexto que foram incluídos os indicadores HHI de competição tanto entre tecnologias como entre empresas com a expectativa de se identificar 
uma relação entre as concentrações de mercado e a penetração do serviço de Banda Larga.

Entretanto, como, na prática, as redes DSL ainda dominam boa parte do mercado, como pode ser visto no Gráfico 3, talvez o nível de competição ainda não tenha alcançado níveis suficientes para serem capturados pelos modelos econométricos (incluindo a variável HHI) como fatores de grande influência sobre a demanda pelo serviço de Banda Larga.

Apesar da cautela necessária, ao se tentar relacionar concentração de mercado e competição, no Brasil, fica patente que a falta de competição no setor é em boa medida responsável pela baixa penetração de Banda Larga, justificando-se assim a implementação de políticas públicas como o Plano Nacional de Banda Larga.

\section{d) População dos municípios}

No primeiro modelo analisado, todas as variáveis apresentaram comportamento dentro do esperado, como demonstrado pelos valores dos coeficientes na Tabela A.1, com exceção da variável população, que apareceu com sinal negativo. Foi verificado que, quando a variável referente ao número de prestadoras presentes no município estava entre as variáveis explicativas, essa inversão de sinal ocorreu. Talvez, isso se explique pela correlação entre estas duas variáveis, como pode ser verificado na Tabela A.1. A correlação ficou próxima de 0,7. Assim, para evitar este comportamento, nos demais modelos foi excluída a variável referente ao número de prestadoras, substituída pelas variáveis referentes ao grau de concentração (e competição) entre empresas e entre tecnologias.

Com esta substituição, a variável população apresentou consistência, estando de acordo com a expectativa inicial de que quanto maior a população do município, maior seria a penetração do serviço de Banda Larga. Isto, devido à economia de escala. Quanto maior a concentração populacional, melhor seria a relação custo-benefício das prestadoras de serviços de telecomunicações, pois, com um mesmo nível de investimento, poderia atingir um público maior, se comparado ao investimento na implantação de redes de Banda Larga em municípios menores.

\section{e) PIB per Capita}

Esta variável apresentou consistência em todos os modelos, ficando dentro do esperado, indicando que quanto maior o grau de riqueza do município, expresso de forma aproximada pelo PIB per capita, maior seria a penetração do serviço de Banda Larga devido ao maior poder de compra da população. 


\section{f) Número de Prestadoras do Serviço de Banda Larga presentes nos municípios}

Na Tabela A.1, vê-se que os coeficientes $\beta_{7}$ (NUM_PRESTADORAS), nos modelos em que foi utilizado, apresentaram valores positivos e elevados.

Nos modelos em que foi incluída, dentre todas as variáveis explicativas analisadas é a que teve maior peso na determinação do número de acessos de Banda Larga no município. Isto também está de acordo com o que se esperava do modelo. Se há muitas operadoras presentes no município, isto é um indicador claro que ali há uma grande demanda pelo serviço e, por isso, o número de acessos é maior.

É possível haver locais com demanda reprimida elevada, mas que não atraiam o interesse das empresas de telecomunicações em oferecer o serviço, devido aos altos investimentos necessários para prover a infra-estrutura necessária a localidade, afastando assim as operadoras.

Deve-se levar em conta que esta variável explicativa tem uma relação de causalidade de mão-dupla com relação ao aumento da penetração do serviço de Banda Larga no município. Ao mesmo tempo que a presença de um número maior de prestadoras no município favorece a difusão do serviço, a perspectiva de demanda elevada pelo serviço no município irá atrair mais empresas de telecomunicações para a localidade. Porém, como o foco desta parte do trabalho não foi o de tentar estabelecer relação de causalidade entre os fatores relacionados com a penetração de Banda Larga e o aumento da difusão do serviço, este é algo que poderia ser abordado em trabalhos futuros.

\section{Conclusão}

Da análise dos coeficientes de regressão apresentada, conclui-se que quanto maior o grau de desenvolvimento do município, maior sua demanda por acesso à internet em Banda Larga. Este grau de desenvolvimento se reflete em diversos indicadores como PIB per capita e acesso a serviços de saúde e educação.

Também ficou evidenciado que quanto maior a parcela do PIB municipal for oriunda de atividades econômicas das áreas de indústria e serviços (em detrimento à área agropecuária), maior a relação com a penetração do serviço de Banda Larga. Isto atendeu às expectativas iniciais de tentar avaliar qual o perfil de município que estaria relacionado com uma maior difusão do serviço de Banda Larga.

Outro fator que correspondeu às expectativas iniciais é o de que quanto maior a disponibilidade de tecnologias de prestação do serviço de Banda Larga presentes no município, mais se induz uma competição, que influencia 
positivamente o aumento da penetração do serviço. Isto decorreria do fato de que na prática, em parte expressiva dos casos, os diversos competidores tendem a se concentrar no uso de uma única tecnologia. Assim, a diversidade de tecnologias reflete esta competição entre empresas, favorecendo o usuário final e aumentando a difusão do serviço.

Entretanto, houve resultados que não corresponderam ao esperado. As análises de regressão, neste caso específico, utilizando este conjunto de dados disponíveis em particular, não indicaram um relacionamento positivo entre aumento da competição entre empresas e aumento da penetração do serviço. Talvez isso se explique pelo alto grau de concentração econômica na exploração do serviço em nível municipal. Os valores encontrados para o índice de concentração de mercado (o índice Herfindahl-Hirschman - HHI) mostrou valores bem elevados para empresas.

A análise se limitou aos dados de indicadores disponíveis, assim, outros fatores que afetam a demanda pelo serviço não puderam ser incluídos, como, por exemplo, se os valores cobrados pelo serviço afetam diretamente sua demanda. Por falta destes dados dos valores cobrados pelo serviço de acesso à internet em Banda Larga pelas prestadoras de telecomunicações desagregados ao nível de município, este importante fator não foi incluído na análise.

De maneira geral, a partir dos resultados das regressões, conclui-se que o principal determinante do aumento da penetração do serviço de acesso à internet em Banda Larga está relacionado com o poder de compra da população. Isto se expressa através de elevação da renda per capita ou da diminuição dos preços cobrados pela prestação do serviço de Banda Larga.

Além da análise econométrica, o estudo permitiu apresentar um panorama da desigualdade na distribuição dos acessos de Banda Larga no país evidenciado nos Gráficos 5 e 6, juntamente com a Figura1.

Também os Gráficos 8, 9 e 10, mostram como o mercado de Banda Larga é concentrado no país. No Gráfico 8 , mostra-se que em quase metade dos municípios a situação é quase de monopólio completo, com o índice HHI próximo de 10.000, o valor máximo.

Nos Gráficos 8 e 9, vê-se que independentemente do tamanho da população do município ou do nível de penetração de Banda Larga. os valores de HHI estão, na sua maioria, acima de 5.000 indicando o mercado dominado por até duas principais empresas, se analisarmos segundo os valores de referência para o HHI da Tabela 2, onde se supõe fatias de mercado iguais para as empresas.

Este cenário de desequilíbrios na distribuição dos acessos e também o excesso de concentração mercadológica demandam uma ação do Estado para 
complementar as falhas do mercado, que até o momento não foi capaz de atender a demanda pelo serviço de forma adequada, pois este concentra a oferta de Banda Larga nas regiões mais ricas, deixando boa parte do país à margem da inclusão digital.

Entre as ações que poderiam ser tomadas pelo poder público para aumentar a penetração de Banda Larga estão:

- Levar redes de fibras ópticas conectando todas as localidades do país, principalmente as pequenas, de forma a garantir que todas tenham conexão de backhaul com capacidade suficiente para escoar o tráfego de internet.

- Incentivar o aumento da competição no setor visando a redução dos preços e o aumento da penetração do serviço, pois, como ficou evidenciado no estudo, o mercado de Banda Larga no Brasil é bastante concentrado. Isto poderia ser feito através de diversas formas:

- O próprio poder público poderia atuar no mercado de atacado ofertando links (enlaces) de dados de alta velocidade, as chamadas linhas dedicadas, a preços razoáveis nas pequenas localidades, permitindo a entrada de novos competidores. Isto iria viabilizar economicamente a operação de pequenos provedores de Banda Larga atuando principalmente nas pequenas cidades, que teriam uma alternativa em relação aos preços elevados praticados pelas operadoras de telefonia fixa que praticamente monopolizam este mercado. Esta é a estratégia delineada pelo Plano Nacional de Banda Larga.

- Implementação de políticas efetivas de compartilhamento de infraestrutura de telecomunicações (unbundling), de forma a permitir que os novos entrantes utilizem a infra-estrutura existente das operadoras de telefonia fixa, que herdaram suas extensas redes com o processo de privatização. Embora isto seja possível, na prática, os preços cobrados pelas detentoras desta infra-estrutura são elevados, inviabilizando a operação e obrigando os novos entrantes a investir na construção de redes próprias. Por outro lado, se os preços fossem muito reduzidos, traria grandes incentivos aos novos entrantes, porém, não incentivaria investimentos das grandes operadoras na ampliação e melhoria de suas redes.

Neste caso, como mencionado em Mattos (2009, p. 254), se a demanda aumenta, os novos entrantes se beneficiam da rede existente, sem precisar fazer novos investimentos em grande escala, e, por outro lado, se a demanda diminui, estas simplesmente não requerem o uso das redes das operadoras existentes. Em ambos os casos, as operadoras existentes arcam com os custos afundados da implantação das redes de telecomunicações. Por isso, a implementação do unblundling deve ser bem ajustada, de forma a beneficiar ambos os lados. 
Hazlett e Weisman (2011, p. 151 e 152) mencionam que uma política de unblundling inadequada pode reduzir excessivamente as margens de lucro das empresas detentoras de extensas redes de infra-estrutura de telecomunicações, aumentando a eficiência estática. Por outro lado, diminuiria a eficiência dinâmica, pois estas empresas teriam menos incentivos e recursos para investimentos na expansão e melhoria de suas redes.

- Incentivar o uso de novas tecnologias de prestação do serviço de Banda Larga. Como ficou evidenciado pela análise de regressão deste estudo, bem como em outros mencionados ao longo do texto, quanto maior a competição entre tecnologias, maior a penetração de Banda Larga. Como mostrado no Gráfico 3, a tecnologia Cable Modem, utilizada pelas operadoras de TV a cabo na prestação de Banda Larga vem ganhando espaço no mercado. Como este serviço depende de concessão do Estado, mudanças na regulamentação poderiam incentivar um aumento na disponibilidade de TV a cabo e, consequentemente, de Banda Larga.

Outras tecnologias, como redes sem fio utilizando os padrões WiMax, WiFi ou redes celulares de $3^{\mathrm{a}}$ geração (3G) com tecnologia WCDMA, também são opções viáveis. Muitas prefeituras implantaram redes WiFi provendo acesso básico gratuito aos munícipes, seguindo a regulamentação da Anatel do Ato n. 66.198 de 27/07/2007. O uso das redes celulares $3 \mathrm{G}$ seria mais uma opção para pequenos municípios, pois, o espectro de radiofrequências disponível para as operadoras de celular ficaria subutilizado se fosse empregado somente para ofertar serviços de voz nestas localidades. Assim, o espectro remanescente poderia ser utilizado para a prestação de Banda Larga móvel, já que, nas pequenas cidades, o tráfego de internet não é tão elevado como nos grandes centros urbanos. A Anatel, através da Resolução n. 537 de 17/02/2010, reservou parte do espectro para o uso da tecnologia WiMax por órgãos da Administração Pública visando a implantação de políticas de inclusão digital. Esta poderia ser utilizada em pequenos municípios.

Como as redes sem fio requerem menores investimentos e podem ser implantadas mais rapidamente que as tradicionais redes com cabos metálicos ou de fibras ópticas, são uma opção viável para a oferta de forma mais imediata de serviços de Banda Larga nos pequenos municípios. Como os núcleos urbanos destes têm pequenas áreas geográficas, podem ser mais facilmente cobertos por redes sem fio, do que as grandes cidades.

\section{Referências bibliográficas}

AGÊNCIA NACIONAL DE TELECOMUNICAÇÕES (Anatel). Relatório Anual de 2008. Brasília, 2009. 75p.

Sistema de Coleta de Informações da Anatel (SICI). Disponível em: http://sistemas.anatel.gov.br/SICI. Acesso em: 18 jun. 2013. 
AGÊNCIA NACIONAL DE TELECOMUNICAÇÕES (Anatel). TV por Assinatura acumula crescimento de 30,7\% em 2010, notícia, 26 jan. 2011, item "Sala de Imprensa Notícias”. Disponível em: http://www.anatel.gov.br. Acesso em: 18 jun. 2013.

ÁVILA, Flávia de Souza. Banda Larga no Brasil: uma análise da elasticidade preçodemanda com base em microdados. 2008. 54p. Tese (Graduação em Economia)Universidade de Brasília, Brasília.

BAIGORRI, C. M.; BOTELHO, T. C. H.; HENRIKSEN, A. L. Análise dos impactos da oferta de TV a Cabo sobre a penetração de banda larga nos municípios brasileiros. Radar Tecnologia, Produção e Comércio Exterior, Instituto de Pesquisa Econômica Aplicada, Brasília, n. 15, p. 29-35, set. 2011.

BENKLER, Y. Next generation connectivity: a review of broadband Internet transitions and policy from around the world. Berkman Center for Internet \& Society at Harvard University, Oct. 2009.

BRASIL. Ministério das Comunicações. Um Plano Nacional Para Banda Larga (PNBL): o Brasil em alta velocidade. Brasília, 2009. 197p.

CARVALHO, A. X. Y.; ALBUQUERQUE, P. H. Tópicos em econometria espacial para dados cross-section. Brasília: Instituto de Pesquisa Econômica Aplicada, ago. 2010. (Textos para Discussão, n. 1508).

COUTINHO, P. C.; OLIVEIRA, A. R Broadband expansion in Brazil: an empirical study. In: ACORN-REDECOM Conference, 4, Brasília. Proceedings... Brasilia, 14-15 maio, 2010. p. 39-58.

CRANDALL, R.; LEHR, W.; LITAN, R. The effects of broadband deployment on output and employment: a cross-sectional analysis of U.S. Data. Issues in Economic Policy, Brookings Institution, n. 6, Jul. 2007.

ESPANHA. Ley 2/2011, de 4 de marzo, de Economía Sostenible, Artículo 52. Boletín Oficial del Estado, Jefatura del Estado, Madrid, Espanha, 5 mar. 2011, n. 55, seção I, p. 25033. Disponível em: <www.boe.es/boe/dias/2011/03/05/pdfs/BOE-A-2011-4117.pdf> Acesso em: 28 jun. 2013.

FEDERAL COMMUNICATIONS COMMISSION (FCC). National Broadband Plan, 2009. Disponível em: http://www.broadband.gov. Acesso em: 19 jun. 2013.

FEDERAÇÃO DAS INDÚSTRIAS DO ESTADO DO RIO DE JANEIRO (FIRJAN). Índice FIRJAN de Desenvolvimento Municipal (IFDM) de 2005. Disponível em: http://www.firjan.org.br. Acesso em: 19 jun. 2013.

GALPERIN, H.; RUZZIER, C. Price elasticity of demand for broadband: evidence from Latin America and the Caribbean. Telecommunications Policy, n. 37, p. 429-438, 2013.

GARCIA-MURILLO, M. International Broadband deployment: the impact of unbundling. Communications \& Strategies, n. 57, p. 83-105, 1st quarter 2005. 
GOMES, P. A. Impactos produtivos do setor de telecomunicações e o desenvolvimento econômico brasileiro no período de 1973 a 2000. 2002. 65p Tese (Mestrado em Economia)-Universidade de Brasília, Brasília.

GUEDES, E. M. et al. Avaliação dos impactos da cisão das operações de STFC e SCM em empresas distintas. Nota técnica. Contribuição à Consulta Pública 23/2008 da Anatel para revisão do plano geral de outorgas. Tendências Consultoria Integrada, jul. 2008. Disponível em: www.anatel.gov.br/Portal/exibirPortalRedireciona.do?codigoDocumento= 216640. Acesso em: 18 jun. 2013.

HAZLETT, T. W.; WEISMAN, D. L. Market power in US Broadband services. Review of Industrial Organization, n. 38, p.151-171, Springer, mar. 2011.

HIRSCHMAN, A. O. The paternity of an index. The American Economic Review, v. 54, n. 5, p. 761, Sept. 1964.

HOLMES, T. J. Structural, experimentalist and descriptive approaches to empirical work in regional economics. Journal of Regional Science, v. 50, n. 1, p. 5-22, 2010.

INSTITUTO BRASILEIRO DE GEOGRAFIA E ESTATÍSTICA (IBGE). Banco de dados com o PIB dos municípios no ano de 2007.

. Banco de dados com estimativas das populações dos municípios.

- Sistema IBGE de Recuperação Automática (SIDRA). 2013. Disponível em: http://www.sidra.ibge.gov.br/. Acesso em: 18 jun. 2013.

INSTITUTO DE PESQUISA ECONÔMICA APLICADA (Ipea). Ipeadata: banco de dados. 2013. Disponível em: http://www.ipeadata.gov.br/. Acesso em: 18 jun. 2013.

- Análise e recomendações para as políticas públicas de massificação de acesso à internet em banda larga. 24p. IPEA, abr. 2010. (Comunicado Ipea, n. 46).

KATZ, R. L. Estimating Broadband demand and its economic impact in Latin America. ACORN-REDECOM Conference, 3. Proceedings... Cidade do México, 22 e 23 de maio de 2009.

KOUTROUMPIS, Pantelis. The economic impact of Broadband on growth: a simultaneous approach. Telecommunications Policy, n. 33, p.471-485, Oct. 2009.

LEE, S.; BROWN. Examining broadband adoption factors: an empirical analysis between countries. Info, v. 10, n. 1, p. 25-39, 2008.

MACEDO, H. R.; CARVALHO, A. X. Y. de. Aumento da penetração do serviço de acesso à Internet em Banda Larga e seu possível impacto econômico: análise através de sistema de equações simultâneas de oferta e demanda. Rio de Janeiro: Ipea, maio 2010. 61p. (Texto para Discussão, n. 1495).

Broadband economic impact in Brazil: a simultaneous equations analysis. In: ACORN-REDECOM Conference, 5. Proceedings... Lima, Peru, May 1920th, 2011. p. 211-228, 
MATTOS, C. Open access policies, regulated charges and non-price discrimination in telecommunications. Information Economics and Policy, n. 21, p. 253-260, jun. 2009.

MAYO, J. W.; WALLSTEN, S. From network externalities to Broadband growth externalities: a bridge not yet built. Review of Industrial Organization, n. 38, p.173-190, Springer, Mar. 2011.

MORAES, R. M. De. O setor de telecomunicações e o crescimento econômico brasileiro: um estudo com dados de painel (2000 a 2005). 2008. 63p.Tese (Mestrado em Economia)Universidade Federal de Pernambuco, Recife.

QIANG, Christine Zhen-Wei; ROSSOTTO, Carlo M.; KIMURA, Kaoru. Economic impacts of Broadband. In: ICAD2009 - Information and Communications for Development: Extending Reach and Increasing Impact, The World Bank, Washington, DC, 2009, Cap. 3, p. $35-50$.

TURNER, S. D. Broadband reality check II - The truth behind America's digital decline. Freepress, Aug. 2006. 44p.

WOHLERS, M. de A. et al. Banda larga no Brasil - por que ainda não decolamos?, Radar - Tecnologia, Produção e Comércio Exterior, Ipea, n. 5, p. 9-15, dez. 2009. 


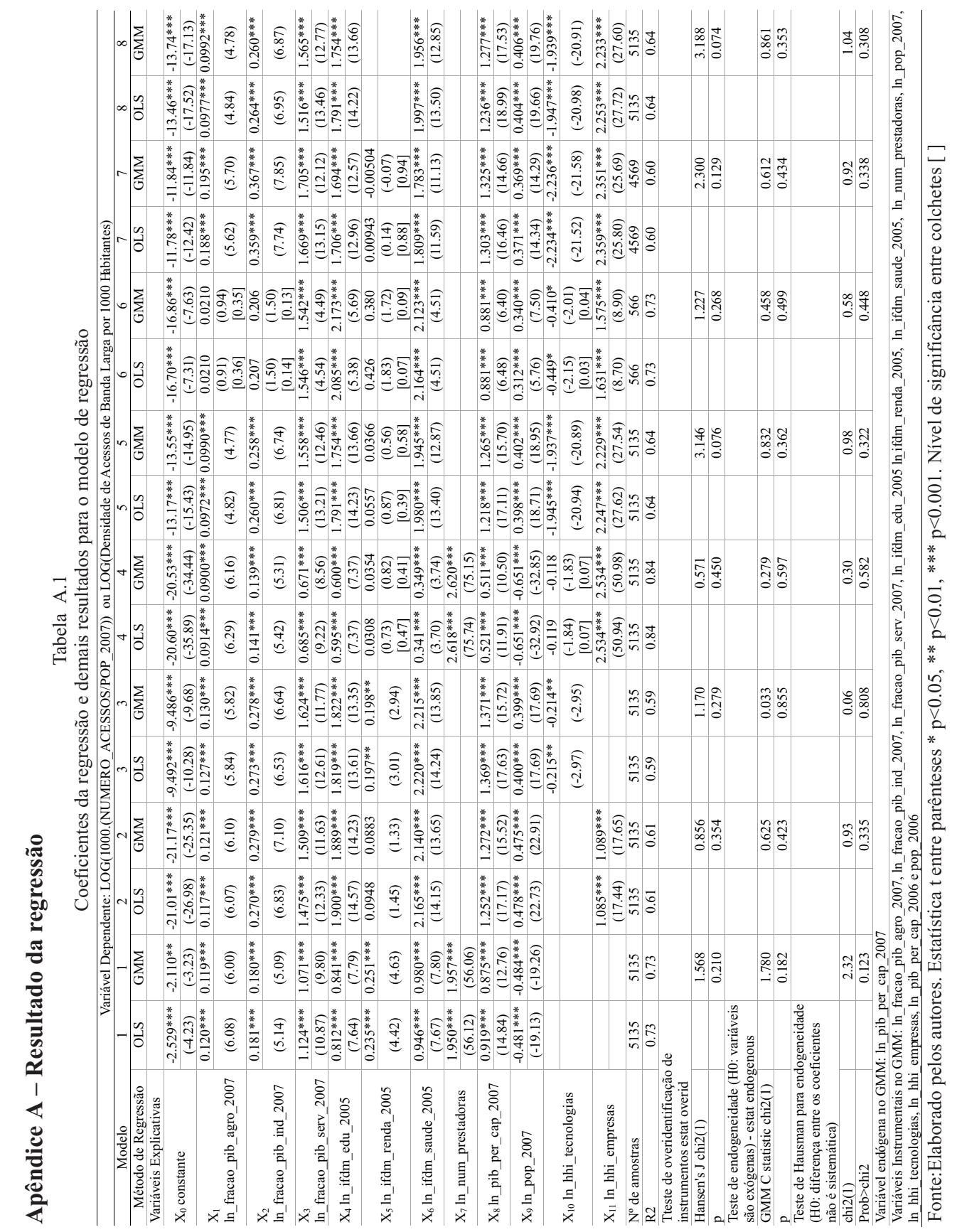




\begin{tabular}{|c|c|c|c|c|c|c|c|c|c|c|c|c|c|c|}
\hline & 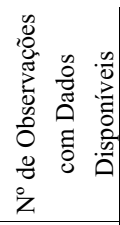 & $\stackrel{m}{n}$ & $\stackrel{m}{n}$ & $\stackrel{m}{n}$ & $\stackrel{\sim}{\tilde{n}}$ & $\stackrel{m}{m}$ & $\stackrel{m}{n}$ & $\frac{m}{n}$ & $\frac{m}{n}$ & $\begin{array}{l}m \\
m \\
m\end{array}$ & & $\hat{m}$ & $\hat{m}$ & $\hat{n}$ \\
\hline & $\begin{array}{l}0 \\
\stackrel{0}{0} \\
\stackrel{\Xi}{0}\end{array}$ & ì & $\overline{\vec{a}}$ & $\begin{array}{l}\vec{b} \\
\stackrel{i}{i}\end{array}$ & $\begin{array}{l}\vec{b} \\
n \\
i\end{array}$ & $\widehat{్}$ & $\stackrel{b}{i}$ & $\begin{array}{l}\stackrel{\infty}{0} \\
\stackrel{0}{0} \\
\stackrel{+}{0}\end{array}$ & $\begin{array}{l}0 \\
\stackrel{0}{h} \\
\dot{a}\end{array}$ & & & $\begin{array}{l}\frac{m}{2} \\
\frac{8}{8}\end{array}$ & 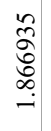 & 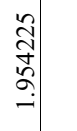 \\
\hline & 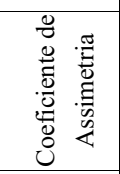 & $\begin{array}{l}\infty \\
\infty \\
0 \\
0\end{array}$ & 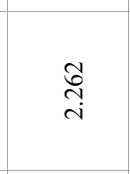 & $\begin{array}{l}n \\
\tilde{n} \\
i \\
i\end{array}$ & $\overrightarrow{\mathrm{\delta}}$ & $\stackrel{r}{\stackrel{0}{0}}$ & 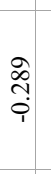 & $\begin{array}{l}\text { aे } \\
\text { fें } \\
\text { in }\end{array}$ & $\frac{2}{6}$ & & $\frac{6}{6}$ & $\stackrel{N}{\stackrel{5}{n}}$ & 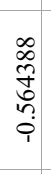 & 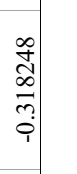 \\
\hline & 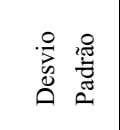 & $\frac{n}{0}$ & $\stackrel{\vec{m}}{0}$ & $\frac{\bar{J}}{0}$ & $\stackrel{\tilde{m}}{0}$ & $\begin{array}{l}\stackrel{\infty}{?} \\
\stackrel{0}{0}\end{array}$ & $\stackrel{?}{0}$ & 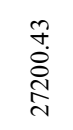 & 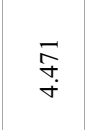 & & $\frac{t}{2}$ & $\begin{array}{l}\text { J్ర } \\
\text { ते }\end{array}$ & $\begin{array}{l}\stackrel{+}{m} \\
\stackrel{+}{+} \\
\stackrel{\sim}{+}\end{array}$ & $\begin{array}{l}\overrightarrow{\dot{b}} \\
\infty \\
\end{array}$ \\
\hline 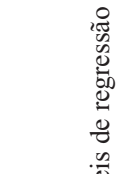 & 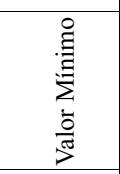 & 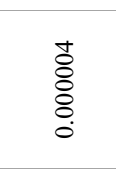 & 兽 & $\stackrel{0}{\circ}$ & 壵 & 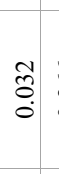 & $\begin{array}{l}\text { : } \\
\stackrel{0}{0}\end{array}$ & - & - & & t & 芯 & 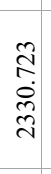 & 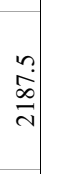 \\
\hline 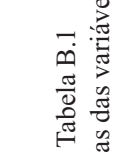 & 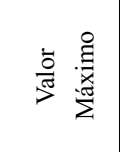 & 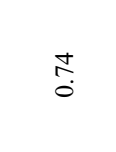 & $\hat{\sigma}$ & $\begin{array}{c}\text { co } \\
\text { co }\end{array}$ & - & \begin{tabular}{l}
$\infty$ \\
$\infty$ \\
\multirow{0}{0}{}
\end{tabular} & - & $\begin{array}{l}\stackrel{\circ}{\circ} \\
\stackrel{0}{\circ} \\
\stackrel{0}{0} \\
-\end{array}$ & $\stackrel{ \pm}{ \pm}$ & & $\begin{array}{l}0 \\
? \\
0 \\
0 \\
0 \\
0 \\
0\end{array}$ & 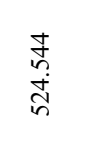 & ๕ి & ‡ \\
\hline 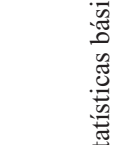 & 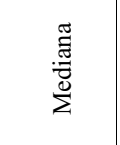 & $\frac{\tilde{\sigma}}{0}$ & $\stackrel{0}{0}$ & 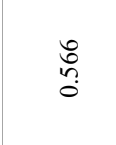 & $\begin{array}{l}\infty \\
0 \\
0 \\
0\end{array}$ & 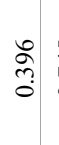 & 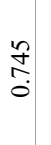 & $\approx$ & n & $\begin{array}{l}\text { R } \\
\stackrel{+}{+}\end{array}$ & $\hat{\overbrace{}}$ & $\stackrel{\tilde{\hat{\alpha}}}{\stackrel{\infty}{-}}$ & 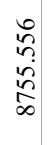 & 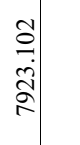 \\
\hline & 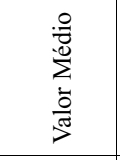 & $\begin{array}{l}\tilde{I} \\
\text { ô. }\end{array}$ & 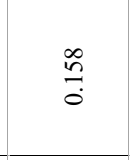 & n̊ & $\begin{array}{l}\tilde{b} \\
0 \\
0\end{array}$ & Fे & $\stackrel{\overbrace{}}{\overbrace{}}$ & 。․ & $\begin{array}{l}\stackrel{a}{0} \\
\dot{+}\end{array}$ & \begin{tabular}{l}
$m$ \\
$\stackrel{0}{0}$ \\
\multirow{2}{*}{} \\
$\alpha$
\end{tabular} & i & $\begin{array}{l}\text { ڤ̊ } \\
\text { త̀ }\end{array}$ & $\begin{array}{l}\infty \\
\infty \\
\infty \\
\dot{\square} \\
\stackrel{n}{\curvearrowright}\end{array}$ & \\
\hline & 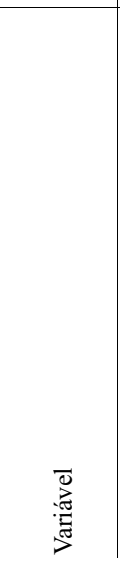 & 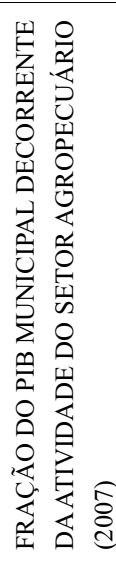 & 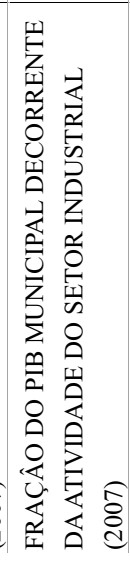 & 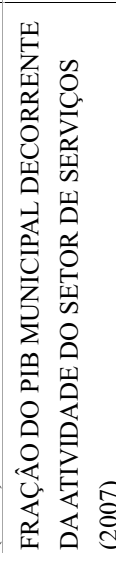 & 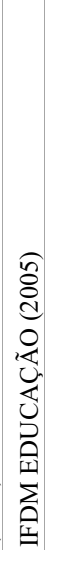 & 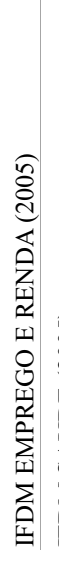 & 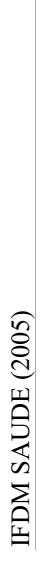 & 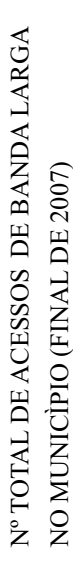 & 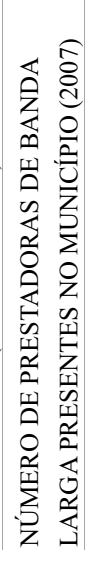 & 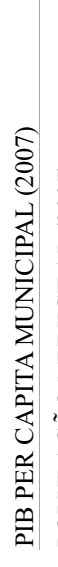 & & 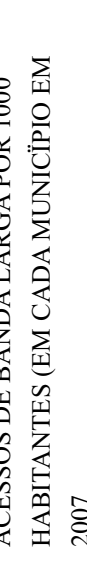 & 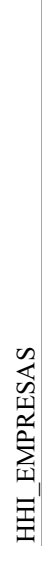 & 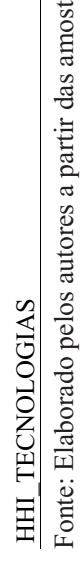 \\
\hline
\end{tabular}


Análise de possíveis determinantes da penetração do serviço de acesso à internet em banda larga...

\section{Apêndice A - Análise de Multicolinearidade}

Na Tabela A.1 estão os valores de coeficientes de correlação entre as variáveis utilizadas no modelo de regressão.

Tabela A.1

Correlações entre as variáveis

\begin{tabular}{|c|c|c|c|c|c|c|}
\hline & $\begin{array}{c}\text { FRACAO } \\
\text { PIB AGRO } \\
2007\end{array}$ & $\begin{array}{c}\text { FRACAO } \\
\text { PIB IND } \\
2007 \\
\end{array}$ & $\begin{array}{c}\text { FRACAO } \\
\text { PIB SERV } \\
2007 \\
\end{array}$ & $\begin{array}{l}\text { IFDM EDU } \\
2005\end{array}$ & $\begin{array}{l}\text { IFDM EMP. } \\
\text { E RENDA }\end{array}$ & $\begin{array}{c}\text { IFDM } \\
\text { SAUDE } \\
2005 \\
\end{array}$ \\
\hline FRACAO PIB AGRO 2007 & 1 & -0.511 & -0.472 & -0.126 & -0.258 & 0.059 \\
\hline FRACAO PIB IND 2007 & -0.511 & 1 & -0.480 & 0.283 & 0.447 & 0.226 \\
\hline FRACAO PIB SERV 2007 & -0.472 & -0.480 & 1 & -0.229 & -0.299 & -0.366 \\
\hline IFDM EDU 2005 & -0.126 & 0.283 & -0.229 & 1 & 0.460 & 0.692 \\
\hline $\begin{array}{l}\text { IFDM EMPREGO E RENDA } \\
2005\end{array}$ & -0.258 & 0.447 & -0.299 & 0.460 & 1 & 0.470 \\
\hline IFDM SAUDE 2005 & 0.059 & 0.226 & -0.366 & 0.692 & 0.470 & 1 \\
\hline $\begin{array}{l}\text { TOTAL ACESSOS NO } \\
\text { MUNICIPIO }\end{array}$ & -0.081 & 0.021 & 0.028 & 0.058 & 0.144 & 0.049 \\
\hline $\begin{array}{l}\text { NUM. PRESTADORAS NO } \\
\text { MUNICIPIO }\end{array}$ & -0.377 & 0.254 & 0.020 & 0.292 & 0.567 & 0.246 \\
\hline PIB PER CAPITA 2007 & -0.070 & 0.471 & -0.488 & 0.346 & 0.448 & 0.382 \\
\hline POP 2007 & -0.156 & 0.056 & 0.053 & 0.056 & 0.235 & 0.045 \\
\hline HHI EMPRESAS & 0.140 & 0.017 & -0.170 & 0.160 & 0.132 & 0.221 \\
\hline HHI TECNOLOG. & 0.152 & -0.099 & -0.033 & -0.034 & -0.093 & 0.002 \\
\hline
\end{tabular}

Tabela C.1 - Continuação

\begin{tabular}{|c|c|c|c|c|c|c|}
\hline & $\begin{array}{c}\text { TOTAL } \\
\text { ACESSOS }\end{array}$ & $\begin{array}{c}\text { No DE } \\
\text { PREST. NO } \\
\text { MUN. }\end{array}$ & $\begin{array}{l}\text { PIB PER } \\
\text { CAP. } 2007\end{array}$ & POP 2007 & $\begin{array}{c}\text { HHI } \\
\text { EMPRESA }\end{array}$ & $\begin{array}{c}\text { HHI } \\
\text { TECNOLOG. }\end{array}$ \\
\hline FRACAO PIB AGRO 2007 & -0.081 & -0.377 & -0.070 & -0.156 & 0.140 & 0.152 \\
\hline FRACAO PIB IND 2007 & 0.021 & 0.254 & 0.471 & 0.056 & 0.017 & -0.099 \\
\hline FRACAO PIB SERV 2007 & 0.028 & 0.020 & -0.488 & 0.053 & -0.170 & -0.033 \\
\hline IFDM EDU 2005 & 0.058 & 0.292 & 0.346 & 0.056 & 0.160 & -0.034 \\
\hline $\begin{array}{l}\text { IFDM EMPREGO E RENDA } \\
2005\end{array}$ & 0.144 & 0.567 & 0.448 & 0.235 & 0.132 & -0.093 \\
\hline IFDM SAUDE 2005 & 0.049 & 0.246 & 0.382 & 0.045 & 0.221 & 0.002 \\
\hline $\begin{array}{l}\text { TOTAL ACESSOS NO } \\
\text { MUNICIPIO } \\
\end{array}$ & 1 & 0.582 & 0.071 & 0.946 & -0.044 & -0.148 \\
\hline $\begin{array}{l}\text { NUM. PRESTADORAS NO } \\
\text { MUNICIPIO }\end{array}$ & 0.582 & 1 & 0.260 & 0.707 & -0.125 & -0.278 \\
\hline PIB PER CAPITA 2007 & 0.071 & 0.260 & 1 & 0.080 & 0.099 & -0.047 \\
\hline POP 2007 & 0.946 & 0.707 & 0.080 & 1 & -0.069 & -0.076 \\
\hline$\underline{\text { HHI EMPRESAS }}$ & -0.044 & -0.125 & 0.099 & -0.069 & 1 & 0.664 \\
\hline FRACAO PIB AGRO 2007 & -0.148 & -0.278 & -0.047 & -0.076 & 0.664 & 1 \\
\hline
\end{tabular}

Fonte: Elaborado pelos autores a partir das amostras. 
Observaram-se correlações maiores que 0,7 para as variáveis:

a) TOTAL ACESSOS x POP 2007: correlação de 0,946. É correlação entre a variável que compõe a variável dependente (TOTAL ACESSOS) e uma das variáveis explicativas (POP 2007). Isto era de se esperar pois quanto maior a população de um município é de se esperar que o número de acessos de Banda Larga seja mais elevado.

b) NUM PRESTADORAS x POP EST 2007: correlação de 0,707. Não representa problema para a regressão pois resultou em baixos valores de desvio padrão para os coeficientes de regressão vinculados a estas variáveis $\boldsymbol{\beta}_{7}, \boldsymbol{\beta}_{\mathbf{9}}$ (aproximadamente 0,05 e 0,03 respectivamente) como pode ser visto a partir dos dados da Tabela A.1, dividindo-se os valores dos coeficientes $\boldsymbol{\beta}$ pelos respectivos valores de estatística t.

Ao se aplicar o logaritmo natural sobre as mesmas variáveis, observaramse correlações maiores que 0,7 para as variáveis Ln(NUM PRESTADORAS) $\mathbf{X}$ Ln(TOTAL ACESSOS), correlação de 0,879 e Ln(NUM PRESTADORAS) X Ln(POP 2007), correlação de 0,725 . São correlações elevadas entre uma variável explicativa e a variável dependente, sendo este tipo de correlação buscado nos modelos. 